Research Article

\title{
On the Finite Element Model of Rotating Functionally Graded Graphene Beams Resting on Elastic Foundation
}

\author{
Nguyen Van Dung, ${ }^{1}$ Nguyen Chi Tho $\mathbb{D}^{2},{ }^{2}$ Nguyen Manh $\mathrm{Ha}^{2}$ and Vu Trong Hieu ${ }^{2}$ \\ ${ }^{1}$ Department of Special Equipments, Le Quy Don Technical University, Ha Noi, Vietnam \\ ${ }^{2}$ Institute of Techniques for Special Engineering, Le Quy Don Technical University, $\mathrm{Ha}$ Noi, Vietnam \\ Correspondence should be addressed to Nguyen Chi Tho; chitho.nguyen@lqdtu.edu.vn
}

Received 4 May 2021; Revised 20 June 2021; Accepted 10 July 2021; Published 27 July 2021

Academic Editor: Rossana Dimitri

Copyright $\odot 2021$ Nguyen Van Dung et al. This is an open access article distributed under the Creative Commons Attribution License, which permits unrestricted use, distribution, and reproduction in any medium, provided the original work is properly cited.

\begin{abstract}
Rotating structures can be easily encountered in engineering practice such as turbines, helicopter propellers, railroad tracks in turning positions, and so on. In such cases, it can be seen as a moving beam that rotates around a fixed axis. These structures commonly operate in hot weather; as a result, the arising temperature significantly changes their mechanical response, so studying the mechanical behavior of these structures in a temperature environment has great implications for design and use in practice. This work is the first exploration using the new shear deformation theory-type hyperbolic sine functions to carry out the free vibration analysis of the rotating functionally graded graphene beam resting on the elastic foundation taking into account the effects of both temperature and the initial geometrical imperfection. Equations for determining the fundamental frequencies as well as the vibration mode shapes of the beam are established, as mentioned, by the finite element method. The beam material is reinforced with graphene platelets (GPLs) with three types of GPL distribution ratios. The numerical results show numerous new points that have not been published before, especially the influence of the rotational speed, temperature, and material distribution on the free vibration response of the structure.
\end{abstract}

\section{Introduction}

Recently, due to the development of science and technology, new materials have been invented and widely applied in engineering practice, in which, materials reinforced by graphene platelets (GPLs) are one of the next-generation structural forms. Graphene-reinforced materials have remarkable characteristics such as a very high Young's modulus, great strength, and excellent thermal conductivity. In addition to the low production cost, the material reinforced by GPL is a relatively good choice to fabricate details and structures in a high load-bearing environment. As a result, researchers worldwide are interested in the mechanical behavior of these structures. Yas and Rahimi [1] carried out the thermal vibration analysis of functionally graded porous nanocomposite beams reinforced by graphene platelets using the Timoshenko beam theory and the generalized differential quadrature method. Also, based on the first-order shear deformation beam theory combined with the differential quadrature method, Song et al. [2] investigated the nonlinear free vibration of edge-cracked graphene nanoplatelet- (GPL-) reinforced composite laminated beams resting on a two-parameter elastic foundation in thermal environments. Barati and Shahverdi [3] studied the forced vibration problem of a nanocomposite beam reinforced with different distributions of graphene platelets in thermal environments using the development of a higherorder refined beam element. Wang and his co-workers [4] used a new Ritz-solution shape function and an improved third-order shear deformation theory to capture the solution for free and forced vibrations of a functionally graded polymer nanocomposite beam reinforced with a low content of graphene oxide and excited by a moving load with a constant velocity. Mojiri and Salami [5] combined both Timoshenko beam theory and generalized differential quadrature method to examine the free vibration and 
dynamic transient response of a multilayer polymer nanocomposite beam resting on an elastic foundation reinforced by graphene platelets nonuniformly distributed through the thickness direction in a thermal environment. Mohammadimehr et al. [6] also used Timoshenko beam theory to conduct a vibration analysis of single-/three-layered micro sandwich beams with porous core and graphene plateletreinforced composite face sheets under magnetic field and elastic foundation. Liu [7] introduced an exact solution of the vibrational characteristics of multilayer magnetic nanocomposite beams reinforced by graphene nanoplatelets. Nematollahi et al. [8] employed a higher-order laminated beam model to find an analytical solution for the nonlinear vibration behavior of thick sandwich nanocomposite beams reinforced by functionally graded graphene nanoplatelet sheets. Tabatabaei-Nejhada and colleagues [9] investigated the out-of-plane vibration characteristics of laminated functionally graded graphene platelets-reinforced composite curved beams bonded by piezoelectric layers using the firstorder shear deformation theory. Manickam et al. [10] used the trigonometric shear flexible beam theory and direct iterative procedure to explore the nonlinear flexural free vibration behavior of size-dependent curved nano/ microbeams with reinforcement of graphene platelets. Based on a refined higher-order shear deformation theory, Arshid and Amir [11] used an analytical method to carry out a vibration analysis of three-layered fluid-infiltrated porous curved microbeams, which were integrated with nanocomposite face sheets reinforced by graphene platelets as lightweight and high-stiffness reinforcements. Zhang et al. [12] presented the vibration analysis of functionally graded graphene platelet-reinforced porous beams resting on a Winkler-Pasternak elastic foundation under a moving load based on the Timoshenko beam theory. Arefi and Najafitabar [13] investigated the buckling and free vibration behavior of sandwich beam, which is composed of a soft core integrated with functionally graded graphene nanoplateletsreinforced composite face sheets. Recently, a variety of studies and presentations of the mechanical response of FG graphene plates with and without elastic foundations have been published [14-22]. Furthermore, the works [23-32] including further intriguing information on the mechanical reaction of beam and plate structures can also be considered.

In practice, some structures can be involved in the rotational movements such as turbines, helicopter propellers, railroad tracks in turning positions, and so on. Thus, it can be seen as a moving beam that rotates around a fixed axis. Due to the presence of additional centrifugal force when participating in the rotation, these beam structures have much nonidentical mechanical behavior compared to conventional beams. Khosravi et al. [33] employed the Timoshenko beam theory and von Kármán type of kinematic assumptions to explore the effect of uniform temperature elevation on the vibration response of the rotating composite beam reinforced with carbon nanotubes. Timoshenko beam theory and von Kármán type of kinematic assumptions were also employed by Kiani et al. [34] to study the buckling behavior of an anisotropic rotating annular plate under a uniformly compressive load on both inner and outer edges. Arvin et al. [35] investigated the free vibration treatment of pre- and post-buckled rotating functionally graded beams by using the Euler-Bernoulli beam theory. Furthermore, the works [33, 35-37] including further intriguing information on the mechanical reaction of beam and plate structures with rotating motion can also be considered. A study of the free vibration of a beam rotating around a fixed axis was recently published [38]; however, it only considered the porous FGM material.

From the short review above, one can see that there are no works dealing with the mechanical behavior of a functionally graded GPL-reinforced composite (FG-GPLRC) beam resting on an elastic foundation, in which the whole structure is embled in a temperature environment, and rotating around one fixed axis. In addition, the initial geometrical imperfection is taken into calculations. So, this work aims to solve this problem using the finite element method combined with the new shear deformation theorytype hyperbolic sine functions, which do not require any shear correction factor but still simulate accurately the mechanical responses of structures. By the numerical results, this paper aims to clearly show the free vibration behavior of the structure taking into account the effect of temperature; thus, there will be special features that have not been mentioned by any work. In addition, the data play an important role in the design and use of GPL-reinforced structures. For example, functionally graded materials with varying microstructures from one material to another one and microstructure sizes ranging over several orders of magnitude may not be adequately modeled using classical continuum mechanics alone but are likely more accurately analyzed using nonclassical continuum mechanics as well as spatial variation (readers can see more in [39]). This study is only concerned with calculating large-scale structures without taking into account the macro level for structures based on continuous mechanics theory, in order to meet the required accuracy.

The rest of this paper is organized as follows. Finite element formulations for free vibration analysis of the rotating FG-GPL beam are clearly presented in Section 2. Verification problems are introduced in Section 3. Numerical data and discussions are given in Section 4. Section 5 draws out some main important novel investigations of this paper.

\section{Finite Formulation of Rotating FG-GPL Beam}

This work concentrates on the vibration response of the rotating FG-GPL beam with the rotational speed $\zeta$, in which the endpoint of the beam is distance $r$ from a fixed axis $Z$. The beam contains an initial geometrical imperfection. The beam operates in a uniformly distributed thermal environment and is supported by a multiple-parameter elastic medium with $k_{w}$ and $k_{s}$ as shown in Figure 1 . The dimensions of the beam are the length $L$, width $b$, and the thickness $h$.

The beam is made from $N_{L}$ GPLRC layers, with the assumption that the GPL reinforcements are randomly oriented and uniformly dispersed with the volume ratio 


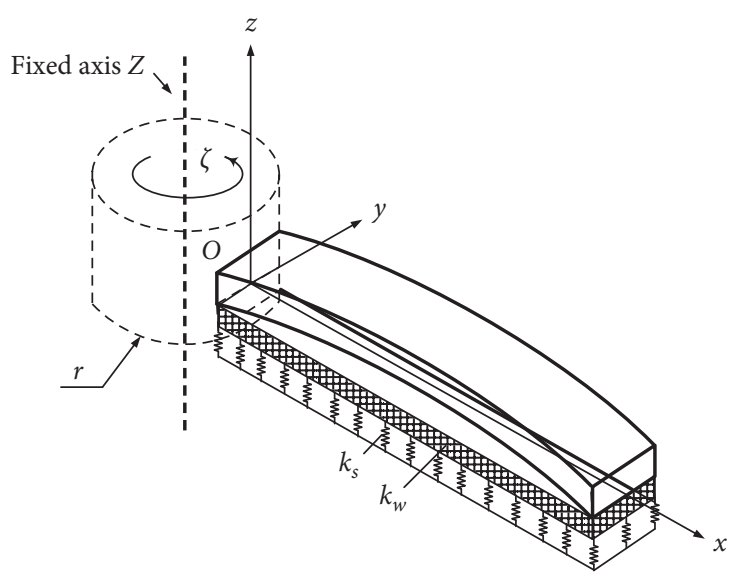

(a)

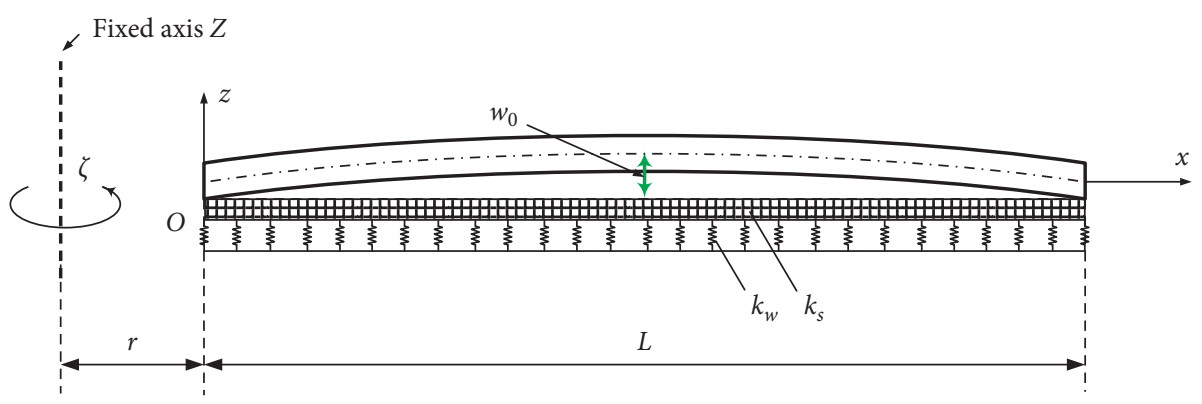

(b)

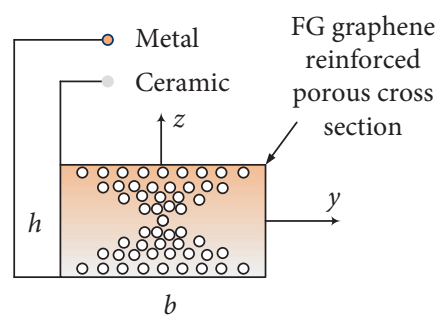

(c)

FIGURE 1: The model of the rotating FG-GPL beam with the initial geometrical imperfection. (a) General view. (b) xOz view. (c) Crosssectional view.

$V_{\mathrm{GPL}}$. In general, three kinds of volume fraction distribution are considered as follows: uniformly distributed GPL type (designated as $\mathrm{U}$ ), functionally graded type (designated as $\mathrm{X}$ and $\mathrm{O}$ ), and layer-wise graded type (designated as $\mathrm{X}$ and $\mathrm{O}$ ). The volume ratio GPL $\left(V_{\mathrm{GPL}}\right)$ for the layer $k$ is defined by the following formula [40]:

$$
\begin{aligned}
& V_{\mathrm{GPL}}^{(k)}=V_{\mathrm{GPL}}^{*}: \mathrm{U}-\mathrm{GPLRC}, \\
& V_{\mathrm{GPL}}^{(k)}=2 V_{\mathrm{GPL}}^{*} \frac{\left|2 k-N_{L}-1\right|}{N_{L}}: \mathrm{X}-\mathrm{GPLRC}, \\
& V_{\mathrm{GPL}}^{(k)}=2 V_{\mathrm{GPL}}^{*}\left(\frac{1-\left|2 k-N_{L}-1\right|}{N_{L}}\right): \mathrm{O}-\mathrm{GPLRC},
\end{aligned}
$$

where $k=1-N_{L}$ and $V_{\mathrm{GPL}}^{*}$ is the total GPL volume fraction, which is calculated as

$$
V_{\mathrm{GPL}}^{*}=\frac{W_{\mathrm{GPL}}}{W_{\mathrm{GPL}}+\left(\rho_{\mathrm{GPL}} / \rho_{m}\right)\left(1-W_{\mathrm{GPL}}\right)},
$$

where $\rho_{\mathrm{GPL}}$ and $\rho_{m}$ are the mass densities of GPLs and matrix and $W_{\mathrm{GPL}}$ is the total GPL weight fraction.

This work employs the modified Halpin-Tsai model, and the GPLRC's effective Young's modulus is estimated by [40]

$$
E=\left(\frac{3}{8}\right) \frac{1+\zeta_{L} \eta_{L} V_{\mathrm{GPL}}}{1-\eta_{L} V_{\mathrm{GPL}}} E_{m}+\left(\frac{5}{8}\right) \frac{1+\zeta_{T} \eta_{T} V_{\mathrm{GPL}}}{1-\eta_{T} V_{\mathrm{GPL}}} E_{m}
$$

where $E_{m}$ is Young's modulus of matrix and $\eta_{L}$ and $\eta_{T}$ are calculated as

$$
\begin{gathered}
\eta_{L}=\frac{\left(E_{\mathrm{GPL}} / E_{m}\right)-1}{\left(E_{\mathrm{GPL}} / E_{m}\right)-\lambda_{L}}, \\
\eta_{T}=\frac{\left(E_{\mathrm{GPL}} / E_{m}\right)-1}{\left(E_{\mathrm{GPL}} / E_{m}\right)-\lambda_{T}},
\end{gathered}
$$

in which $E_{\mathrm{GPL}}$ is Young's modulus of GPLs and $\lambda_{L}$ and $\lambda_{T}$ are GPL geometry factors taking the following forms:

$$
\begin{aligned}
& \lambda_{L}=2\left(\frac{a_{\mathrm{GPL}}}{b_{\mathrm{GPL}}}\right)\left(\frac{b_{\mathrm{GPL}}}{t_{\mathrm{GPL}}}\right), \\
& \lambda_{T}=2\left(\frac{b_{\mathrm{GPL}}}{t_{\mathrm{GPL}}}\right),
\end{aligned}
$$

where $a_{\mathrm{GPL}}, b_{\mathrm{GPL}}$, and $t_{\mathrm{GPL}}$ are the GPL length, width, and thickness, respectively. The mass density $\rho$, thermal expansion coefficient $\alpha$, and Poisson's ratio $v$ of GPLRCs are calculated according to the formula presented in [40].

There have been numerous shear deformation theories to explore the mechanical behavior of beam structures, in which each one includes its advantages. Recently, there is a new type of shear deformation theory that has been developed and employed widely called hyperbolic sine functions $[41,42]$. So, this paper also aims to use this new theory 
to establish the finite element formulations of free vibration problems of rotating FGM beams. Therefore, the displacement field at any point $M(x, z)$ in the beam has the following expression:

$$
\left\{\begin{array}{l}
U_{1}(x, z)=U_{1 m}(x, y)-z \frac{\partial U_{3 b}}{\partial x}-f(z) \frac{\partial U_{3 s}}{\partial x} \\
U_{3}(x, z)=U_{3 b}+U_{3 s}+U_{3 \mathrm{imp}}(x)
\end{array}\right.
$$

in which $U_{1 m}$ is the displacement in the $x$-direction at the neutral axis and $f(z)=z-h \sinh (z / h)+z \cosh (1 / 2)$.

The expressions of longitudinal displacement $\wp_{x}$, shear displacement $\xi_{x z}$, and thermal displacement $\wp_{T}$ of the beam are calculated as

$$
\begin{aligned}
\wp_{x}= & \frac{\partial U_{1}}{\partial x}=\frac{\partial U_{1 m}}{\partial x}-z \frac{\partial^{2} U_{3 b}}{\partial x^{2}}-g(z) \frac{\partial^{2} U_{z s}}{\partial x^{2}} \\
& +\frac{d U_{3 \operatorname{imp}}}{d x} \frac{\partial\left(U_{3 b}+U_{3 s}\right)}{\partial x} \\
= & \frac{\partial U_{1 m}}{\partial x}+z\left(-\frac{\partial^{2} U_{3 b}}{\partial x^{2}}\right)+g(z)\left(-\frac{\partial^{2} U_{3 s}}{\partial x^{2}}\right) \\
& +\frac{d U_{3 i m p}}{d x} \frac{\partial\left(U_{3 b}+U_{3 s}\right)}{\partial x} \\
= & \wp_{1 m}+z \wp_{1 b}+g(z) \wp_{1 s}+\wp_{1 \mathrm{imp}} \\
\xi_{x z}= & \frac{\partial g(z)}{\partial z} \frac{\partial U_{3 s}}{\partial x}=\frac{\partial g(z)}{\partial z} \xi_{13 s} \\
\wp_{T}= & \alpha\left(T-T_{0}\right)=\alpha \Delta T,
\end{aligned}
$$

in which $\Delta T$ is the temperature difference $T$ compared to room temperature $T_{0}$, and the strain components are expressed as

$$
\begin{aligned}
\wp_{1 m} & =\frac{\partial U_{1 m}}{\partial x}, \\
\wp_{1 b} & =\left(-\frac{\partial^{2} U_{3 b}}{\partial x^{2}}\right), \\
\wp_{1 s} & =\left(-\frac{\partial^{2} U_{3 s}}{\partial x^{2}}\right), \\
\wp_{\text {imp }} & =\frac{d U_{3 \operatorname{imp}}}{d x} \frac{\partial\left(U_{3 b}+U_{3 s}\right)}{\partial x} .
\end{aligned}
$$

Assuming the material operates within an elastic limit, according to the Hook law, the normal stress $\Xi_{x}$, thermal stress $\Xi_{T}$, and shear stress $\Theta_{x z}$ are expressed as follows:

$$
\begin{aligned}
\Xi_{x} & =E \wp_{x}, \\
\Xi_{T} & =E \wp_{T}, \\
\Theta_{x z} & =\frac{E}{2(1+v)} \xi_{x z} .
\end{aligned}
$$

The elastic energy of the FGM beam is calculated as

$$
\begin{aligned}
\Pi^{E}= & \frac{1}{2} \int_{V}\left(\Xi_{x}^{T} \wp_{x x}+\Theta_{x z}^{T} \xi_{x z}\right) \mathrm{d} V \\
= & \frac{1}{2} \int_{V}\left(\begin{array}{c}
\wp_{1 m}^{T} E \wp_{1 m}+\wp_{1 m}^{T} z E \wp_{1 b}+\wp_{1 m}^{T} g(z) E \wp_{1 s}+\wp_{1 m}^{T} E \wp_{1 \mathrm{imp}} \\
\wp_{1 b}^{T} E z \wp_{1 m}+\wp_{1 b}^{T} E z^{2} \varepsilon_{x b}+\wp_{1 b}^{T} E z g(z) \wp_{1 s}+\wp_{1 b}^{T} E z \wp_{1 \mathrm{imp}} \\
\wp_{1 s}^{T} E g(z) \wp_{1 m}+\wp_{1 s}^{T} \varepsilon_{x s}^{T} E z g(z) \varepsilon_{x b}+\wp_{1 s}^{T} E(z) g^{2}(z) \wp_{1 s}+\wp_{1 s}^{T} E g(z) \wp_{1 \mathrm{imp}} \\
\wp_{1 x m p}^{T} E \wp_{1 m}+\wp_{1 x m p}^{T} E z \varepsilon_{x b}+\wp_{1 \mathrm{imp}}^{T} E g(z) \wp_{1 s}+\wp_{1 \mathrm{imp}}^{T} E \wp_{1 \mathrm{imp}}
\end{array}\right) \mathrm{d} V \\
& +\frac{1}{2} \int_{V}\left(\begin{array}{c}
\left(\frac{\partial g(z)}{\partial z}\right)^{2} \frac{E}{2(1+\nu)} \xi_{13 s}^{T} \xi_{13 s}
\end{array}\right) \mathrm{d} V .
\end{aligned}
$$

The energy of the elastic foundation is defined as

$$
\Pi^{F}=\frac{1}{2} b \int_{L}\left(k_{w}\left(U_{3 b}+U_{3 s}\right)^{2}+k_{s}\left(\frac{\partial\left(\left(U_{3 b}+U_{3 s}\right)\right)}{\partial x}\right)^{2}\right) \mathrm{d} x \text {. }
$$

When the FGM beam involves rotational movement around one fixed axis with the speed $\zeta$, the potential energy of the beam generated by this rotational movement is calculated as $[43,44]$ 


$$
\Pi^{\zeta}=\frac{1}{2} \int_{L}\left(P_{\zeta}(x)\left(\frac{\partial\left(U_{3 b}+U_{3 s}\right)}{\partial x}\right)^{2}\right) \mathrm{d} x,
$$

in which the centrifugal force $P_{\zeta}$ is defined as [43]

$$
P_{\zeta}=\frac{1}{2} \int_{S}\left(\rho(z) \zeta^{2}\left[r(L-x)+\frac{1}{2}\left(L^{2}-x^{2}\right)\right]\right) \mathrm{d} S .
$$

The work done by temperature acting in the longitudinal direction of the GPLR beam is defined as

$$
\Pi^{\text {ther }}=\frac{1}{2} \int_{V}\left(\Xi_{T}\left(\frac{\partial\left(U_{3 b}+U_{3 s}\right)}{\partial x}\right)^{2}\right) \mathrm{d} V .
$$

The kinetic energy expression of the beam is calculated as

$$
\Pi^{k}=\frac{1}{2} \int_{V} \rho(z)\left(\left(\frac{\partial \dot{U}_{1}}{\partial t}\right)^{T}\left(\frac{\partial \dot{U}_{1}}{\partial t}\right)+\left(\frac{\partial \dot{U}_{3}}{\partial t}\right)^{T}\left(\frac{\partial \dot{U}_{3}}{\partial t}\right)\right) \mathrm{d} V
$$

To establish the equilibrium equation of the FGM beam, this paper employs Hamilton's principle as follows:

$$
\delta \int_{t_{1}}^{t_{2}}\left(\Pi^{k}-\Pi^{E}-\Pi^{F}-\Pi^{R o}\right) \mathrm{d} t=0 .
$$

Herein, this paper employs a two-node beam element, in which each node has five degrees of freedom:

$$
\mathbf{u}_{e}=\sum_{i=1}^{2}\left\{\begin{array}{c}
U_{1 m} \\
U_{3 b i} \\
U_{3 s i} \\
\left(\frac{\partial U_{3 b}}{\partial x}\right)_{i} \\
\left(\frac{\partial U_{3 s}}{\partial x}\right)_{i}
\end{array}\right\}
$$

where the displacements at each point in the beam element are approximated through Lagrange and Hermite interpolation functions $N_{i}$ and $H_{i}$.

$$
\left\{\begin{array}{l}
U_{1 m}=\sum_{i=1}^{2} N_{i} U_{1 m i}=\mathbf{N}_{u} \mathbf{u}_{e}, \\
U_{3 b}=\sum_{i=1}^{2}\left\{H_{i} U_{3 b i}+H_{i+1}\left(\frac{\partial U_{3 b}}{\partial x}\right)_{i}\right\}=\mathbf{H}_{b} \mathbf{u}_{e}, \\
\frac{\partial U_{3 b}}{\partial x}=\sum_{i=1}^{2}\left\{\frac{\partial H_{i}}{\partial x} U_{3 b i}+\frac{\partial H_{i+1}}{\partial x}\left(\frac{\partial U_{3 b}}{\partial x}\right)_{i}\right\}=\mathbf{H}_{b x} \mathbf{u}_{e} \\
\left.\frac{\partial U_{3 s}}{\partial x}=\sum_{i=1}^{2}\left\{\frac{\partial H_{i}}{\partial x} U_{3 s i}+\frac{\partial H_{i+1}}{\partial x}\left(\frac{\partial U_{3 s}}{\partial x}\right)_{i}\right\}=H_{i+1}\left(\frac{\partial U_{3 s}}{\partial x}\right)_{i}\right\}=\mathbf{H}_{s} \mathbf{u}_{e}, \\
\frac{\partial^{2} U_{3 b}}{\partial x^{2}}=\sum_{i=1}^{2}\left\{\frac{\partial^{2} H_{i}}{\partial x^{2}} U_{3 b i}+\frac{\partial^{2} H_{i+1}}{\partial x^{2}}\left(\frac{\partial U_{3 b}}{\partial x}\right)_{i}\right\}=\mathbf{H}_{b 2 x} \mathbf{u}_{e} \\
\frac{\partial^{2} U_{3 s}}{\partial x^{2}}=\sum_{i=1}^{2}\left\{\frac{\partial^{2} H_{i}}{\partial x^{2}} U_{3 s i}+\frac{\partial^{2} H_{i+1}}{\partial x^{2}}\left(\frac{\partial U_{3 s}}{\partial x}\right)_{i}\right\}=\mathbf{H}_{s 2 x} \mathbf{u}_{e}
\end{array}\right.
$$

Equation (18) can be shortened in the matrix form as follows:

$$
\mathbf{u}=\left\{\begin{array}{c}
U_{1 m} \\
U_{3 b} \\
U_{3 s} \\
\left(\frac{\partial U_{3 b}}{\partial x}\right) \\
\left(\frac{\partial U_{3 s}}{\partial x}\right)
\end{array}\right\}=\left[\begin{array}{c}
\mathbf{N}_{u} \\
\mathbf{H}_{b} \\
\mathbf{H}_{s} \\
\mathbf{H}_{b x} \\
\mathbf{H}_{s x}
\end{array}\right] \mathbf{u}_{e}=\mathbf{H} \mathbf{u}_{e}
$$

The strains are defined according to the nodal displacement as follows: 


$$
\left\{\begin{array}{l}
\wp_{1 m}=\frac{\partial U_{1 m}}{\partial x}=\frac{\partial \mathbf{N}_{u}}{\partial x} \mathbf{u}_{e}=\mathbf{B}_{u} \mathbf{u}_{e} \\
\wp_{1 b}=-\frac{\partial^{2} U_{3 b}}{\partial x^{2}}=-\mathbf{H}_{b 2 x} \mathbf{u}_{e}=\mathbf{B}_{b} \mathbf{u}_{e} \\
\wp_{1 s}=-\frac{\partial^{2} U_{3 s}}{\partial x^{2}}=-\mathbf{H}_{s 2 x} \mathbf{u}_{e}=\mathbf{B}_{s} \mathbf{u}_{e} \\
\wp_{1 \mathrm{imp}}=\frac{\partial\left(U_{3 b}+U_{3 s}\right)}{\partial x} \frac{d U_{3 \mathrm{imp}}}{d x}=\frac{d U_{3 \mathrm{imp}}}{d x}\left(\mathbf{H}_{b}+\mathbf{H}_{s}\right) \mathbf{u}_{e}=\mathbf{B}_{\mathrm{imp}} \mathbf{u}_{e} \\
\xi_{13 s}=\frac{\partial U_{3 s}}{\partial x}=\mathbf{H}_{s x} \mathbf{u}_{e} .
\end{array}\right.
$$$$
\text { Now, the expression of the elastic energy of the beam }
$$

$$
\begin{aligned}
& \Pi_{e}^{E}=\frac{1}{2} \mathbf{u}_{e}^{T} \int_{V}\left(\begin{array}{c}
\mathbf{B}_{u}^{T} E \mathbf{B}_{u}+\mathbf{B}_{u}^{T} z E \mathbf{B}_{b}+\mathbf{B}_{u}^{T} g(z) E \mathbf{B}_{s}+\mathbf{B}_{u}^{T} E \mathbf{B}_{\mathrm{imp}} \\
\mathbf{B}_{b}^{T} E z \mathbf{B}_{u}+\mathbf{B}_{b}^{T} E z^{2} \mathbf{B}_{b}+\mathbf{B}_{b}^{T} E z g(z) \mathbf{B}_{s}+\mathbf{B}_{b}^{T} E z \mathbf{B}_{\mathrm{imp}} \\
\mathbf{B}_{s}^{T} E g(z) \mathbf{B}_{u}+\mathbf{B}_{s}^{T} E z g(z) \mathbf{B}_{b}+\mathbf{B}_{s}^{T} E g^{2}(z) \mathbf{B}_{s}+\mathbf{B}_{s}^{T} E g(z) \mathbf{B}_{\mathrm{imp}} \\
\mathbf{B}_{\mathrm{imp}}^{T} E \mathbf{B}_{u}+\mathbf{B}_{\mathrm{imp}}^{T} E z \mathbf{B}_{b}+\mathbf{B}_{\mathrm{imp}}^{T} E g(z) \mathbf{B}_{s}+\mathbf{B}_{\mathrm{imp}}^{T} E \mathbf{B}_{\mathrm{imp}}
\end{array}\right) \mathrm{d} V \mathbf{u}_{e} \\
& +\frac{1}{2} \mathbf{u}_{e}^{T} \int_{V}\left(\left(\frac{\partial g(z)}{\partial z}\right)^{2} \frac{E}{2(1+\nu)} \mathbf{H}_{s x}^{T} \mathbf{H}_{s x}\right) \mathrm{d} V \mathbf{u}_{e} \\
& =\frac{1}{2} \mathbf{u}_{e}^{T} \int_{V}\left(\begin{array}{c}
\mathbf{B}_{u}^{T} E \mathbf{B}_{u}+\mathbf{B}_{u}^{T} z E \mathbf{B}_{b}+\mathbf{B}_{u}^{T} g(z) E \mathbf{B}_{s}+\mathbf{B}_{u}^{T} E \mathbf{B}_{\mathrm{imp}} \\
\mathbf{B}_{b}^{T} E z \mathbf{B}_{u}+\mathbf{B}_{b}^{T} E z^{2} \mathbf{B}_{b}+\mathbf{B}_{b}^{T} E z g(z) \mathbf{B}_{s}+\mathbf{B}_{b}^{T} E z \mathbf{B}_{\mathrm{imp}} \\
\mathbf{B}_{s}^{T} E g(z) \mathbf{B}_{u}+\mathbf{B}_{s}^{T} E z g(z) \mathbf{B}_{b}+\mathbf{B}_{s}^{T} E g^{2}(z) \mathbf{B}_{s}+\mathbf{B}_{s}^{T} E g(z) \mathbf{B}_{\mathrm{imp}} \\
\mathbf{B}_{\mathrm{imp}}^{T} E \mathbf{B}_{u}+\mathbf{B}_{\mathrm{imp}}^{T} E z \mathbf{B}_{b}+\mathbf{B}_{\mathrm{imp}}^{T} E f(z) \mathbf{B}_{s}+\mathbf{B}_{\mathrm{imp}}^{T} E \mathbf{B}_{\mathrm{imp}}
\end{array}\right) \mathrm{d} V \mathbf{u}_{e} \\
& +\frac{1}{2} \mathbf{u}_{e}^{T} \int_{V}\left(\left(\frac{\partial g(z)}{\partial z}\right)^{2} \frac{E}{2(1+\nu)} \mathbf{H}_{s x}^{T} \mathbf{H}_{s x}\right) \mathrm{d} V \mathbf{u}_{e}
\end{aligned}
$$

Equation (21) can be shortened in the matrix form as

$$
\Pi_{e}^{E}=\frac{1}{2} \mathbf{u}_{e}^{T} \mathbf{K}_{e}^{E} \mathbf{u}_{e} .
$$

The energies of the centrifugal inertia force and the elastic foundation are calculated, respectively, as follows: 


$$
\begin{aligned}
& \Pi_{e}^{F}=\frac{1}{2} \mathbf{u}_{e}^{T}\left(b \int_{L}\left(k_{w}\left(\mathbf{H}_{b}+\mathbf{H}_{s}\right)^{T}\left(\mathbf{H}_{b}+\mathbf{H}_{s}\right)+k_{s}\left(\mathbf{H}_{b x}+\mathbf{H}_{s x}\right)^{T}\left(\mathbf{H}_{b x}+\mathbf{H}_{s x}\right)\right) \mathrm{d} x\right) \mathbf{u}_{e}=\frac{1}{2} \mathbf{u}_{e}^{T} \mathbf{K}_{e}^{F} \mathbf{u}_{e}, \\
& \Pi_{e}^{R}=\frac{1}{2} \mathbf{u}_{e}\left(b \int_{L}\left\{P_{\Theta}(x)\left(\mathbf{H}_{b x}+\mathbf{H}_{s x}\right)^{T}\left(\mathbf{H}_{b x}+\mathbf{H}_{s x}\right)\right\} \mathrm{d} x\right) \mathbf{u}_{e}=\frac{1}{2} \mathbf{u}_{e}^{T} \mathbf{K}_{e}^{R} \mathbf{u}_{e} .
\end{aligned}
$$

The energy due to thermal strain is calculated as

$$
\Pi^{\text {ther }}=\frac{1}{2} \mathbf{u}_{e}^{T}\left\{b \int_{L}\left(E \alpha \Delta T\left(\mathbf{H}_{b x}+\mathbf{H}_{s x}\right)^{T}\left(\mathbf{H}_{b x}+\mathbf{H}_{s x}\right)\right) \mathrm{d} x\right\} \mathbf{u}_{e}=\frac{1}{2} \mathbf{u}_{e}^{T} \mathbf{K}_{e}^{\text {ther }} \mathbf{u}_{e} .
$$

The kinetic energy of the FGM beam element is defined as follows:

$$
\Pi_{e}^{k}=\frac{1}{2} \int_{V}\left(\dot{u}_{e}^{T} \rho(z) \dot{u}_{e}\right) \mathrm{d} V=\frac{1}{2} \dot{u}_{e}^{T}\left(\int_{V}\left(\mathbf{H}^{T} \mathbf{H}\right) \mathrm{d} V\right) \dot{u}_{e}=\frac{1}{2} \dot{u}_{e}^{T}\left(\mathbf{M}_{e}\right) \dot{u}_{e},
$$

where $\mathbf{M}_{e}=\int_{V} \rho(z)\left(\mathbf{H}^{T} \mathbf{H}\right) \mathrm{d} V$ is the element stiffness matrix.

By substituting equations (21)-(23) into (16), the equation to obtain the fundamental frequency, as well as the vibration mode shapes of the rotating FGM beam, can be expressed as follows:

$$
\left\{\sum_{e}\left(\mathbf{K}_{e}^{E}+\mathbf{K}_{e}^{F}+\mathbf{K}_{e}^{R}-\mathbf{K}_{e}^{\text {ther }}\right)-\omega^{2} \sum_{e} \mathbf{M}_{e}\right\} \sum_{e} \psi_{e}=0 .
$$

Equation (26) shows that all constituents relating to rotational movement, elastic foundation, and initial geometrical imperfection are presented in the equation for finding the fundamental vibration behavior of the FGM beam, and this is completely different from conventional beam structures; therefore, this makes the computation more complicated in comparison with previous works. By looking at the established calculation formulas, the reader may see that the approach employed in this work is based on the theory of shear strain hyperbolic sine functions, which does not require shear correction. The reason is that the shear correction factor is dependent on the structure's material, and it is difficult to predict its value precisely; therefore, the theory utilized in this study will more accurately explain the structure's reaction than the first-order shear strain theory. Furthermore, the separation of $z$-axis displacement into two components related to bending $\left(U_{3 b}\right)$ and shear $\left(U_{3 s}\right)$ allows the mechanical response of the beam to be precisely described. Because the shear strain theory used in this study has fewer components than higher-order shear strain theories, it takes less time to compute.

Boundary conditions are defined by the following expressions:

(i) Simply supported (denoted as $S$ ):

$$
\begin{aligned}
& u_{0}=0, \\
& w_{b}=0, \\
& w_{s}=0 .
\end{aligned}
$$

(ii) Clamped (denoted as $C$ ):

$$
\begin{gathered}
u_{0}=0, \\
w_{b}=0, \\
w_{s}=0, \\
\frac{\partial w_{b}}{\partial x}=0, \\
\frac{\partial w_{s}}{\partial x}=0 .
\end{gathered}
$$

In this work, three boundary conditions are considered for calculations of FGM beams.

(iii) Fully clamped beam: C-C.

(iv) Fully simply supported beam: S-S.

One side is clamped, the other side is free: C-F. 
Table 1: First three nondimensional fundamental frequencies $(\widetilde{\omega})$ of the beam subjected to the axial load $\bar{N}=0.6$.

\begin{tabular}{lccccccccc}
\hline $\begin{array}{l}\text { Boundary } \\
\text { condition }\end{array}$ & $\begin{array}{c}\text { Vibration } \\
\text { mode }\end{array}$ & $\begin{array}{c}\text { Exact } \\
{[45]}\end{array}$ & $\begin{array}{c}\text { Exact } \\
{[46]}\end{array}$ & $\begin{array}{c}\text { FEM with } 8 \\
\text { elements [47] }\end{array}$ & $\begin{array}{c}4 \\
\text { elements }\end{array}$ & $\begin{array}{c}6 \\
\text { elements }\end{array}$ & $\begin{array}{c}\text { This work } \\
\text { elements }\end{array}$ & $\begin{array}{c}10 \\
\text { elements }\end{array}$ & $\begin{array}{c}12 \\
\text { elements }\end{array}$ \\
\hline \multirow{3}{*}{ S-S } & 1 & 6.24 & - & 6.24 & 6.247 & 6.243 & 6.242 & 6.242 & 6.241 \\
& 2 & 36.40 & - & 36.41 & 36.505 & 36.402 & 36.383 & 36.377 & 36.375 \\
& 3 & 85.81 & - & 85.93 & 61.891 & 85.924 & 85.768 & 85.721 & 85.703 \\
\hline & 1 & - & 13.01 & 13.01 & 13.018 & 13.006 & 13.003 & 13.003 & 13.003 \\
S-C & 2 & - & 47.35 & 47.38 & 47.493 & 47.356 & 47.323 & 47.313 & 47.309 \\
& 3 & - & 101.54 & 101.73 & 101.053 & 101.630 & 101.450 & 101.384 & 101.358 \\
\hline
\end{tabular}

\section{Verification Problems}

Firstly, this section introduces five examples to evaluate the reality of the proposed approach and mechanical models, where the numerical results of these examples are compared with those of other exact works.

Example 1. At first, this example collates the natural frequency of the homogeneous beam subjected to the axial compressive load. Geometrical and material characteristics are the length $L$, cross section $b \times h, L / h=100, E=380 \mathrm{GPa}$, $\nu=0.3$, and $\rho=3960 \mathrm{~kg} / \mathrm{m}^{3}$. The structure is subjected to an axial compressive load $N_{0}$, where $\bar{N}=\left(N_{0} L^{2} / \pi^{2} \mathrm{EI}_{0}\right)=0.6$. The nondimensional fundamental frequency is normalized by the formula $\widetilde{\omega}=\omega \sqrt{\left(\rho b h L^{4} / \mathrm{EI}_{0}\right)}\left(I_{0}=b h^{3} / 12\right)$. The data obtained from this example, exact expressions $[45,46]$, and FEM modeling [47] are presented in Table 1, when this example calculates using a variety of different meshes. It can be observed that when the mesh size increases, the numerical results ensure the necessary convergence. The results in this work with the 8-element mesh size are different from the data of the same mesh size used in [47]. The cognition is that reference [47] employed Timoshenko's first-order shear deformation theory. So, for the 8-element mesh, the accuracy is fine; thus, this mesh size is going to be used for all the following related explorations.

Example 2. The natural frequency of the FG-GPLRC beam generated from this case is then compared to the finite element method (FEM) [3], which utilized a refined beam theory. The geometry and material specifications are described in [3], with $L / h=10$ and $W_{\mathrm{GPL}}=1 \%$ for a uniformly GPL-reinforced beam. The nondimensional fundamental frequencies $\widehat{\omega}=\omega L^{2} \sqrt{\rho_{m} A / E_{m} I}$ are compared, where $A=b . h, I=b \cdot h^{3} / 12$. Table 2 shows the calculation and comparison results, which demonstrate that as the mesh size increases, the results converge to a frequency value that is near to the frequency calculated using the finite element approach [3] (based on a refined beam theory which is different from the beam theory used in this work). This shows that the approach employed in this study ensures the requisite level of dependability.

Example 3. Next, the fundamental frequency of the fully simply supported $\mathrm{Al} / \mathrm{Al}_{2} \mathrm{O}_{3}$ beam resting on Winkler-Pasternak elastic foundation is considered.
Geometrical and material characteristics are the length $L$, thickness $h, L / h=100$, width $b, E_{m}=70 \mathrm{GPa}, \rho_{m}=2702 \mathrm{~kg} /$ $\mathrm{m}^{3}, E_{c}=380 \mathrm{GPa}$, and $\rho_{m}=396 \mathrm{~kg} / \mathrm{m}^{3}$. Two elastic foundation parameters are normalized as follows:

$$
\left\{\begin{array}{l}
\bar{K}_{w}=\frac{K_{1} L^{4}}{E_{m} I}, \\
\bar{K}_{s}=\frac{K_{2} L^{2}}{E_{m} I \pi^{2}},
\end{array}\right.
$$

with

$$
I=\frac{b h^{3}}{12}
$$

The nondimensional fundamental frequency of the beam is defined as follows:

$$
\widehat{\omega}=\omega_{1} \frac{L^{2}}{h} \sqrt{\frac{\rho_{m}}{E_{m}}}
$$

Table 3 shows the comparative first fundamental frequency of the beam obtained from this work and the analytical method [48]. It can be seen that with 8 elements, the reliability is acceptable; thus, this work will use this mesh for all the following related investigations.

Example 4. This example considers the fundamental frequency of the fully simply supported beam with an initial geometrical imperfection. The beam contains geometrical and material parameters $L=288.7 \mathrm{~h}, \quad h=0.02 \mathrm{~m}, b=0.04 \mathrm{~m}$, $E=971 \mathrm{GPa}$, and mass density $\rho=2300 \mathrm{~kg} / \mathrm{m}^{3}$. An initial imperfection of the beam is expressed as $w_{\text {im }}(x)=J_{0} \sin (\pi x)$, where $J_{0}$ is the amplitude of the imperfection. The nondimensional fundamental frequency and the initial imperfection coefficient $\varsigma_{0}$ are normalized as follows:

$$
\begin{aligned}
\omega^{* *} & =\omega_{1} \sqrt{\frac{12 \rho L^{4}}{E h^{2}}}, \\
\varsigma_{0} & =\frac{J_{0}}{L} .
\end{aligned}
$$

The numerical results obtained from this example and the pseudo-arclength continuation technique [49] in the case of increasing gradually the value of $\varsigma_{0}$ are presented in 
TABLE 2: The dependence of the first nondimensional fundamental frequency $(\widehat{\omega})$ of the FG-GPLRC beam on the mesh size.

\begin{tabular}{|c|c|c|c|c|c|c|c|c|c|}
\hline \multirow{2}{*}{ Method } & \multicolumn{9}{|c|}{ Element numbers } \\
\hline & 2 & 3 & 4 & 5 & 10 & 12 & 20 & 30 & 35 \\
\hline This work & 19.7928 & 19.7559 & 19.7488 & 19.7468 & 19.7454 & 19.7454 & 19.7454 & 19.7454 & 19.7454 \\
\hline [3] & 20.8610 & 20.7961 & 20.7846 & 20.7814 & 20.7794 & 20.7793 & 20.7792 & 20.7792 & 20.7792 \\
\hline
\end{tabular}

TABLE 3: The first nondimensional fundamental frequency $(\widehat{\omega})$ of the beam resting on Winkler-Pasternak elastic foundation, $\bar{K}_{w}=10, \bar{K}_{s}=1$, S-S.

$a / h=100$

This work

$n$ Mode Analytical method [48]

\begin{tabular}{|c|c|c|c|c|c|c|c|c|}
\hline & & & Anaryica & 6 elements & 8 elements & 10 elements & 12 elements & 14 elements \\
\hline \multirow{9}{*}{$\begin{array}{l}\text { Without elastic foundation } \\
\bar{K}_{w}=10 \\
\bar{K}_{s}=0\end{array}$} & \multirow{3}{*}{0} & 1 & 5.483 & 5.483 & 5.483 & 5.483 & 5.483 & 5.483 \\
\hline & & 2 & 21.933 & 21.931 & 21.924 & 21.922 & 21.921 & 21.921 \\
\hline & & 3 & 49.350 & 49.389 & 49.318 & 49.296 & 49.288 & 49.284 \\
\hline & \multirow{3}{*}{1} & 1 & 4.221 & 4.220 & 4.220 & 4.220 & 4.220 & 4.220 \\
\hline & & 2 & 16.884 & 16.884 & 16.879 & 16.877 & 16.876 & 16.876 \\
\hline & & 3 & 37.989 & 38.030 & 37.975 & 37.958 & 37.952 & 37.949 \\
\hline & \multirow{3}{*}{2} & 1 & 3.852 & 3.851 & 3.851 & 3.851 & 3.851 & 3.851 \\
\hline & & 2 & 15.407 & 15.408 & 15.403 & 15.402 & 15.401 & 15.401 \\
\hline & & 3 & 34.666 & 34.707 & 34.657 & 34.641 & 34.635 & 34.633 \\
\hline \multirow{9}{*}{$\begin{array}{l}\text { With elastic foundation } \\
\bar{K}_{w}=10 \\
\bar{K}_{s}=1\end{array}$} & \multirow{3}{*}{0} & 1 & 6.015 & 6.014 & 6.014 & 6.014 & 6.014 & 6.014 \\
\hline & & 2 & 22.445 & 22.442 & 22.436 & 22.434 & 22.433 & 22.433 \\
\hline & & 3 & 49.858 & 49.891 & 49.824 & 49.803 & 49.796 & 49.792 \\
\hline & \multirow{4}{*}{1} & 1 & 5.008 & 5.007 & 5.007 & 5.007 & 5.007 & 5.007 \\
\hline & & 2 & 17.666 & 17.664 & 17.660 & 17.659 & 17.658 & 17.658 \\
\hline & & 3 & 38.77 & 38.801 & 38.753 & 38.738 & 38.732 & 38.729 \\
\hline & & 1 & 4.752 & 4.752 & 4.752 & 4.752 & 4.752 & 4.752 \\
\hline & \multirow[t]{2}{*}{2} & 2 & 16.316 & 16.315 & 16.311 & 16.310 & 16.310 & 16.309 \\
\hline & & 3 & 35.577 & 35.606 & 35.564 & 35.550 & 35.545 & 35.543 \\
\hline
\end{tabular}

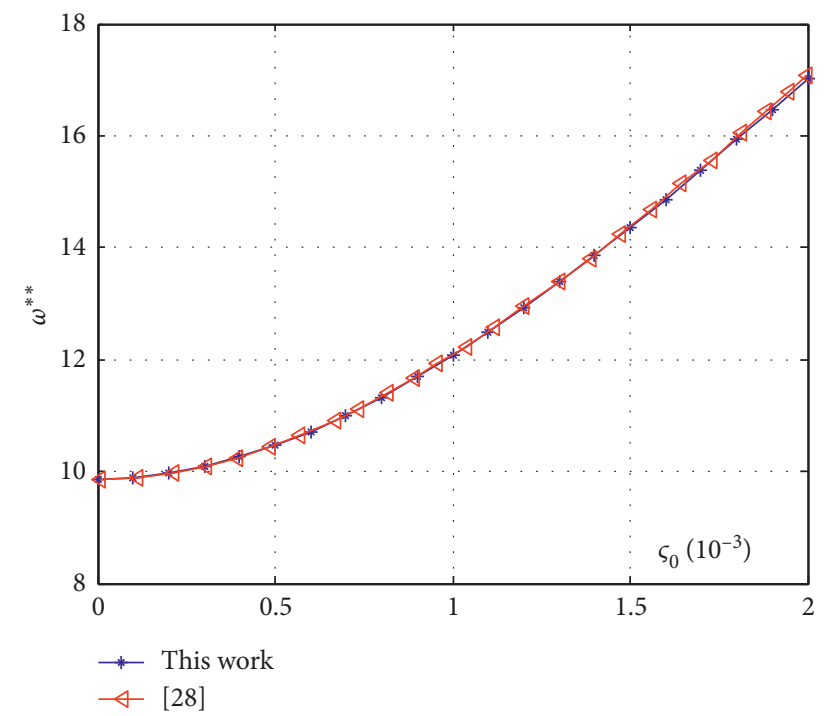

FIgURE 2: The dependence of the first nondimensional fundamental frequency of the beam with the initial geometrical imperfection on the imperfection coefficient $\varsigma_{0}$. 
TABLE 4: The dependence of the first three nondimensional fundamental frequencies $\left(\bar{\omega}_{i}\right)$ of the cantilever rotational beam on rotational speed $\bar{\xi}$.

\begin{tabular}{|c|c|c|c|c|c|}
\hline \multirow{2}{*}{ Vibration mode } & \multirow{2}{*}{ Method } & \multicolumn{4}{|c|}{ Rotational speed ratio $\bar{\xi}$} \\
\hline & & $\bar{\xi}=0$ & $\bar{\xi}=3$ & $\bar{\xi}=6$ & $\bar{\xi}=12$ \\
\hline \multirow{4}{*}{$\widetilde{\omega}_{1}$} & This work & 3.5161 & 4.6790 & 7.0734 & 12.6098 \\
\hline & Exact [50] & 3.5160 & 4.7973 & 7.3604 & 13.1702 \\
\hline & $\mathrm{DMM}[51]$ & 3.5160 & 4.7973 & 7.3604 & - \\
\hline & Isogeometric [43] & 3.5118 & 4.7733 & 7.3276 & - \\
\hline \multirow{4}{*}{$\widetilde{\omega}_{2}$} & This work & 22.0247 & 23.1197 & 26.1110 & 36.4500 \\
\hline & Exact $[50]$ & 22.0345 & 23.3203 & 26.8091 & 37.6031 \\
\hline & DMM [51] & - & - & - & - \\
\hline & Isogeometric [43] & - & - & - & - \\
\hline \multirow{4}{*}{$\widetilde{\omega}_{3}$} & This work & 61.6254 & 62.7602 & 66.0242 & 77.4512 \\
\hline & Exact $[50]$ & 61.6972 & 62.9850 & 66.6840 & 79.6145 \\
\hline & DMM [51] & - & - & - & - \\
\hline & Isogeometric [43] & - & - & - & - \\
\hline \multirow{4}{*}{$\widetilde{\omega}_{4}$} & This work & 120.647 & 121.843 & 125.348 & 138.295 \\
\hline & Exact $[50]$ & 120.902 & 122.236 & 126.140 & 140.534 \\
\hline & DMM [51] & - & - & - & - \\
\hline & Isogeometric [43] & - & - & - & - \\
\hline
\end{tabular}

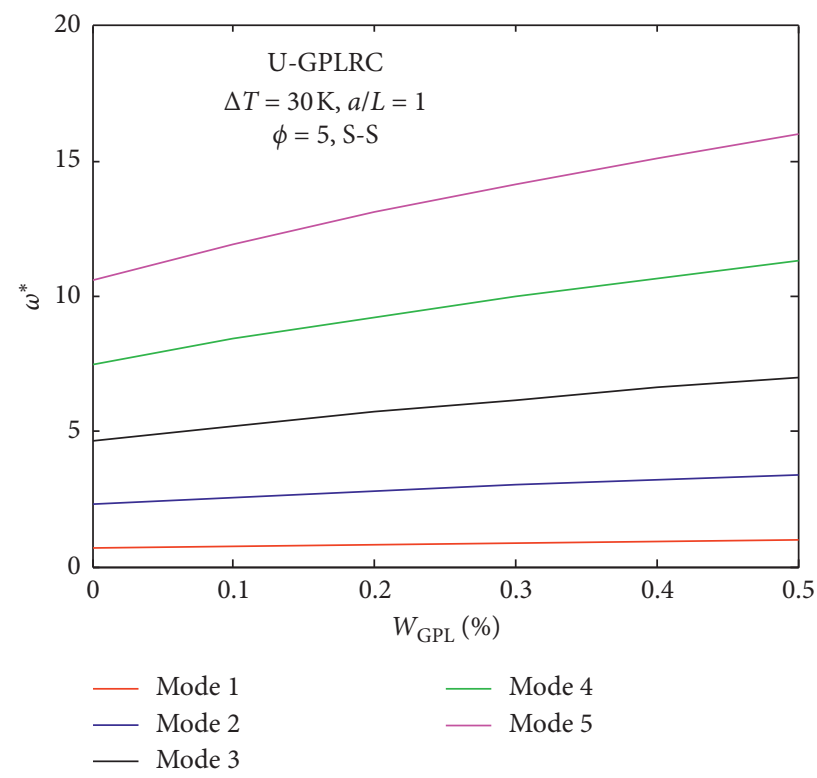

(a)

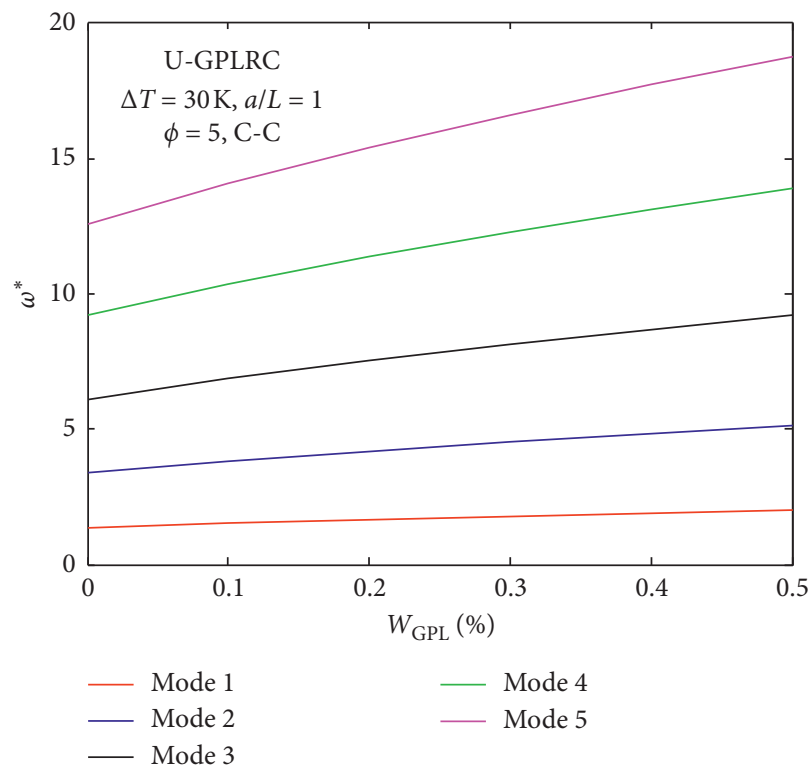

(b)

FIGURE 3: The dependence of the first five natural frequencies of the rotating U-GPLRC beam on the GPL weight fractions, $\gamma_{0}=0.001$, $K_{w}^{*}=20, K_{s}^{*}=5$. (a) S-S. (b) C-C.

Figure 2. An excellent match can be seen between the numerical findings and the outcome.

Example 5. Finally, this example presents a verification problem of the cantilever rotating beam with the rotational speed $\chi$. Let us consider a beam with the following geometrical and material properties: the length $L$, thickness $h=b=L / 100$, $r=0, E=70 \mathrm{GPa}$, and mass density $\rho=2700 \mathrm{~kg} / \mathrm{m}^{3}$. The nondimensional fundamental frequency $\widetilde{\omega}_{i}$ is defined as follows:

$$
\bar{\omega}_{i}=\omega_{i} L^{2} \sqrt{\frac{12 \rho}{E h^{2}}} .
$$

The first three nondimensional fundamental frequencies of the rotating beam with different values of the rotational speed ratio $\bar{\xi}=L^{2} \Theta \sqrt{12 \rho / E h^{2}}$ obtained from this example, an exact solution [50], an isogeometric analysis [43], and a new dynamic modeling method (DMM) [51] are presented in Table 4. 


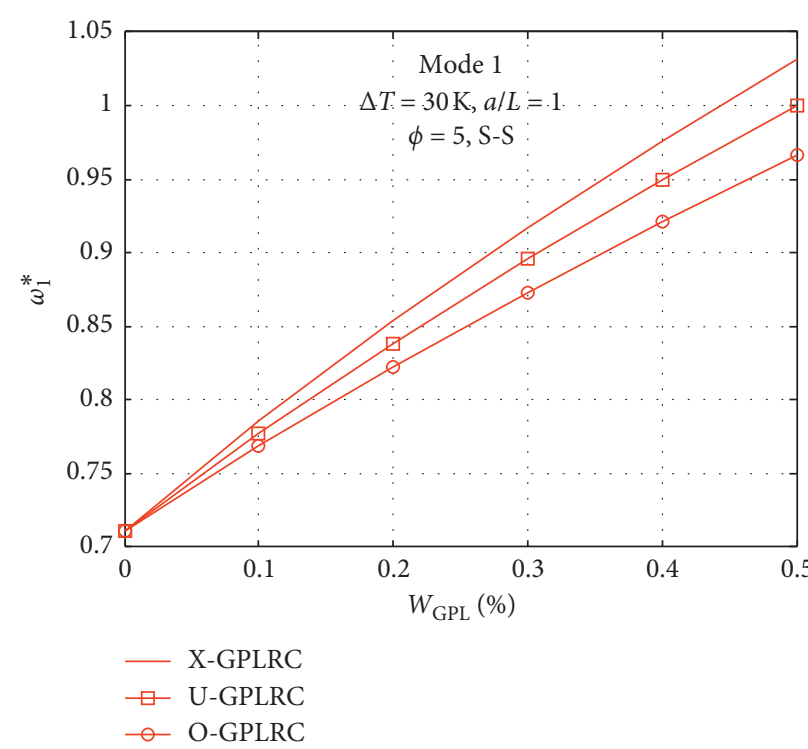

(a)

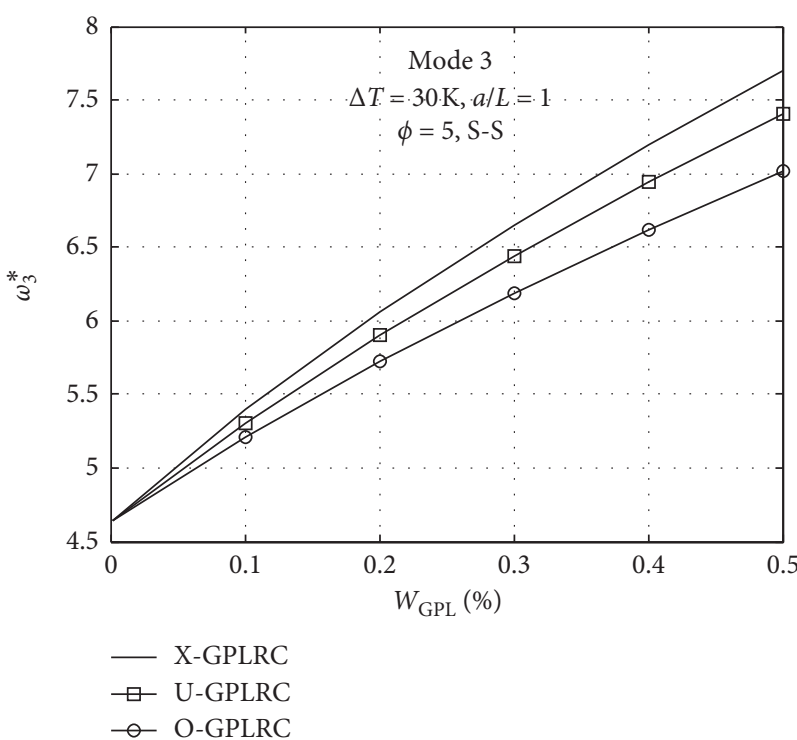

(c)

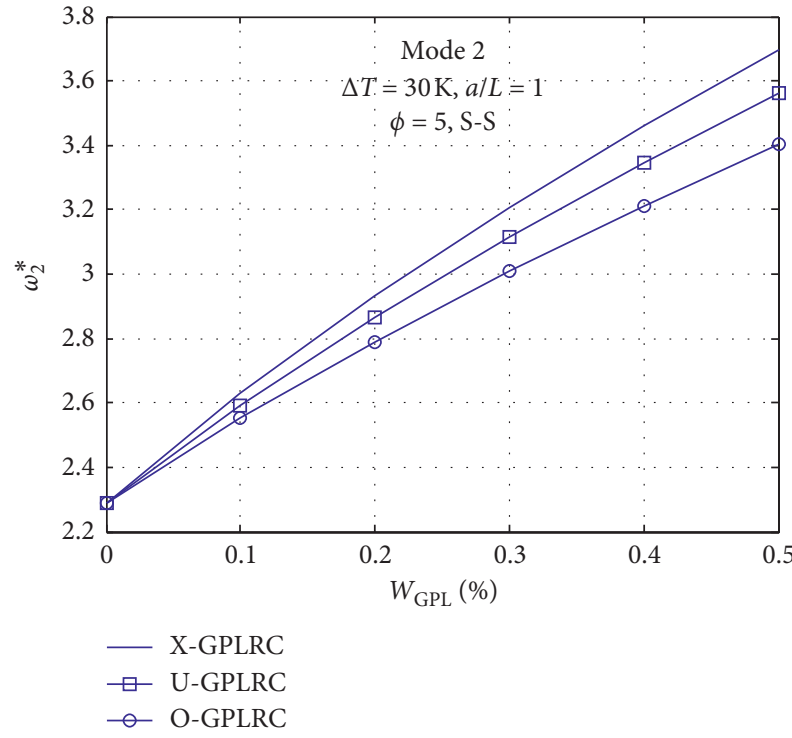

(b)

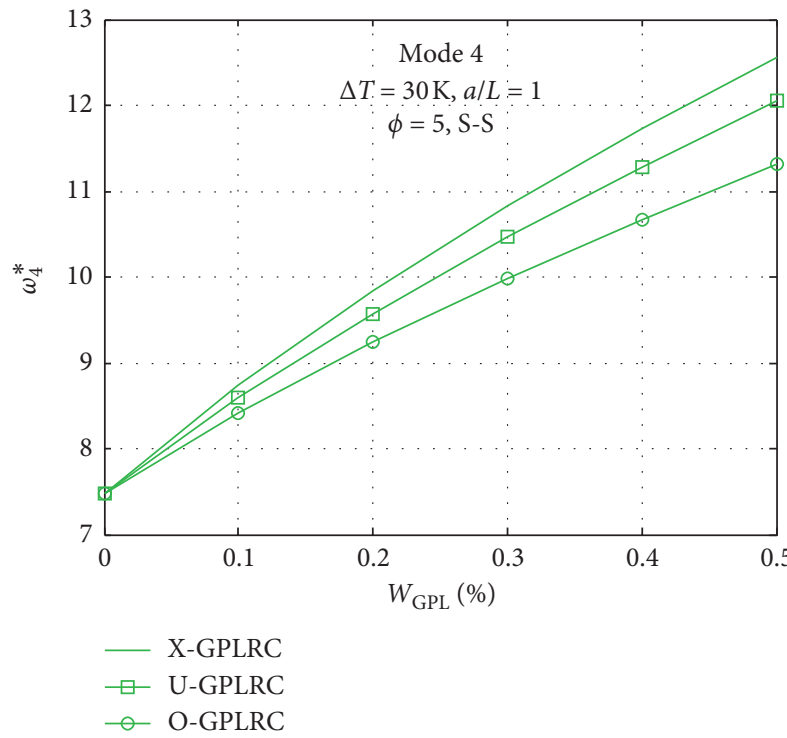

(d)

FIGURE 4: The dependence of the first four natural frequencies of the rotating X-, U-, and O-GPLRC beams on the GPL weight fractions, $\gamma_{0}=0.001, K_{w}^{*}=20, K_{s}^{*}=5$. (a) Mode 1. (b) Mode 2. (c) Mode 3. (d) Mode 4.

\section{Numerical Results}

Now, this section presents the vibration analysis of the rotating porosity FGM beam resting on Winkler-Pasternak elastic foundation under the pre-axial compressive load, in which the initial geometrical imperfection is taken into account. Let us consider a beam with the following geometrical and material characteristics: the length $L$, cross section $b \times h$, thickness $h, L /$ $h=10, a_{\mathrm{GPL}}=2.5 \mu \mathrm{m}, b_{\mathrm{GPL}}=1.5 \mathrm{~nm}, t_{\mathrm{GPL}}=2.5 \mu \mathrm{m}, E_{\mathrm{GPL}}=$ $1.01 \mathrm{TPa}, \quad v_{\mathrm{GPL}}=0.186, \quad \alpha_{\mathrm{GPL}}=5.10^{-6} 1 / \mathrm{K}, \quad \rho_{\mathrm{GPL}}=$ $1062 \mathrm{~kg} / \mathrm{m}^{3}, E_{\mathrm{m}}=3.0 \mathrm{GPa}, v_{m}=0.34, \alpha_{m}=60.10^{-6} 1 / \mathrm{K}$, and $\rho_{m}=1200 \mathrm{~kg} / \mathrm{m}^{3}$. The imperfection of beam is $w_{0}(x)=M_{0} \sin (\pi x)$, in which $M_{0}$ is the amplitude of 


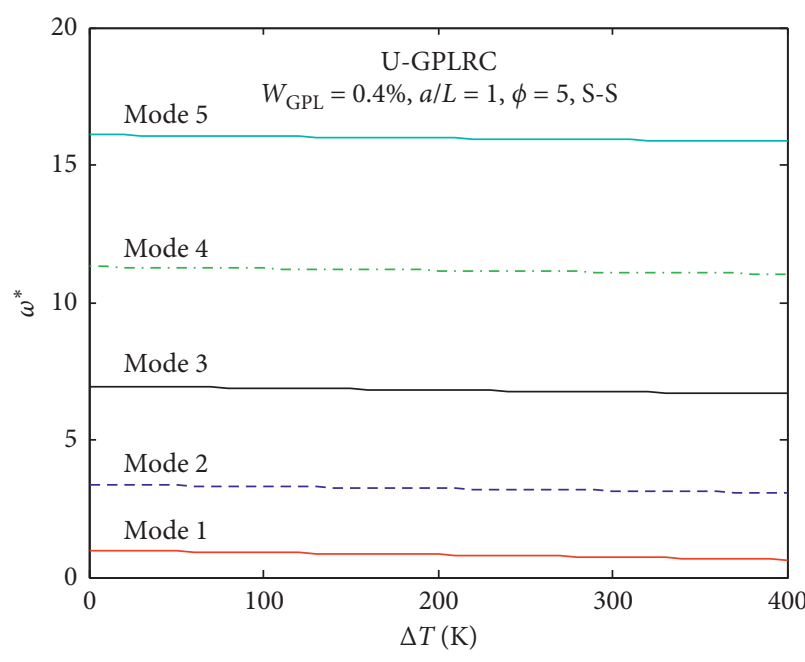

(a)

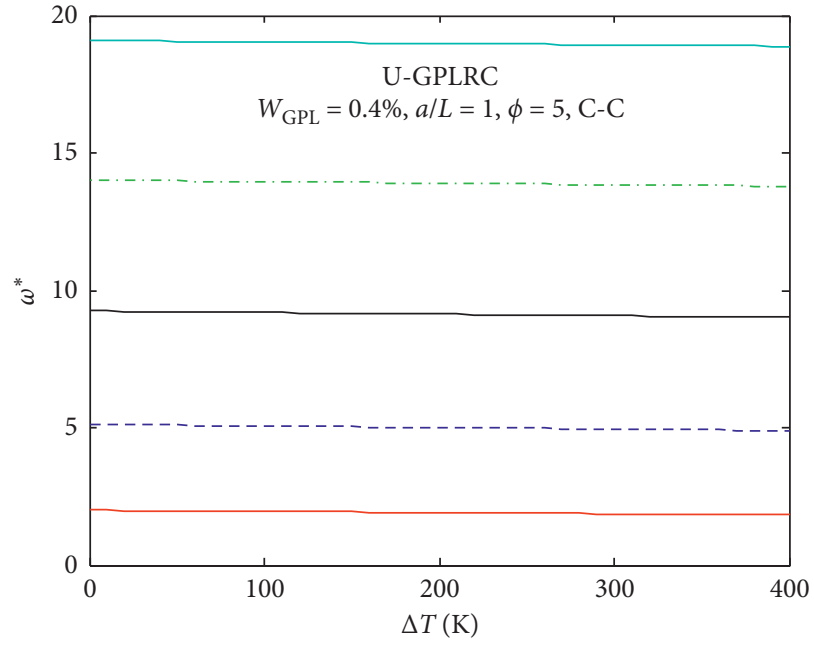

(b)

FIGURE 5: The dependence of the first five natural frequencies of the rotating U-GPLRC beam on $\Delta T, \gamma_{0}=0.001, K_{w}^{*}=20, K_{s}^{*}=5 .(\mathrm{a}) \mathrm{S}-\mathrm{S}$. (b) C-C.

imperfection and the imperfection ratio is $\gamma_{0}=M_{0} / L$. The nondimensional fundamental frequency and other parameters are calculated as follows:

$$
\begin{aligned}
\omega_{i}^{*} & =\omega_{i} L \sqrt{\frac{\rho_{m}}{E_{m}}}, \\
K_{w}^{*} & =\frac{k_{w} L^{4}}{\bar{D}_{m}}, \\
K_{s}^{*} & =\frac{k_{s} L^{2}}{\bar{D}_{m}}, \\
\phi & =L^{2} \zeta^{\frac{12 \rho_{m}}{E_{m} h_{0}^{2}}}, \\
\bar{D}_{m} & =\frac{E_{m} h_{0}^{3}}{12} .
\end{aligned}
$$

4.1. Effect of the GPL Weight Fractions. Firstly, this section examines the effect of the GPL weight fractions on the vibration behavior of the GPLR beam. The beam has $L /$ $h=10$, imperfection ratio $\gamma_{0}=0.001$, two elastic foundation parameters $K_{w}^{*}=20, K_{s}^{*}=5$, distance ratio $a / L=1$, rotational speed $\phi=5$, and $\Delta T=30 \mathrm{~K}$. We change the GPL weight fractions so that $W_{\mathrm{GPL}}$ obtains the values in a range of $0-0.5 \%$. The first five nondimensional frequencies of the rotating U-GPLRC beam depending on $W_{\mathrm{GPL}}$ with two boundary conditions are presented in Figures 3, and 4 presents the dependence of the first five nondimensional frequencies on $W_{\mathrm{GPL}}$ of the X-GPLRC, U-GPLRC, and O-GPLRC beams. One can see the following.

When increasing the GPL weight fractions $W_{\mathrm{GPL}}$, the frequencies of the structure rise as the GPL weight grows. $W_{\mathrm{GPL}}$, in turn, determines the first five frequencies of the beam in a nonlinear manner. However, it is much more obvious when looking at the higher frequencies, since there is a nonlinear relationship between these dependence on the $W_{\mathrm{GPL}}$ coefficient.

When increasing the coefficient $W_{\mathrm{GPL}}$, the X- GPLRC beam has the highest natural frequency, and the O-GPLRC beam has the lowest frequency. This proves that the law of material distribution affects the mass and stiffness of the GPLR beam at the same time; as a result, the frequencies of this beam are different.

4.2. Effect of Temperature. This section investigates the effect of the temperature on the free vibration response of the beam. Consider a beam with $L / h=10, \gamma_{0}=0.001$, and two elastic foundation parameters $K_{w}^{*}=20, K_{s}^{*}=5$. We change the acting temperature on the beam so that $\Delta T$ varies from 0 to $400 \mathrm{~K}$. The dependencies of the first five natural frequencies of the beam on the temperature with two cases of boundary conditions S-S and C-C are shown in Figure 5. Figure 6 presents the dependence of the first four natural frequencies of the beam on the temperature with three cases of material distribution for S-S boundary. The first natural frequency of the beam depending on the $W_{\mathrm{GPL}}$ ratio is presented in Figure 7 . The numerical data point out the following.

As the temperature increases, the natural frequencies for all three cases of material distribution decrease. At different temperatures, the natural frequency of the $\mathrm{X}-\mathrm{GPLRC}$ beam has the largest natural frequency, while the natural frequency of the O-GPLRC beam has the smallest value.

Interestingly, drawn from Figure 7, there exists a value of temperature for any value of the WGPL coefficient the first natural frequency of the beam does not change; in other words, there exists a value of temperature whose first natural frequency of the beam does not depend on the ratio of the graphene material, called $\Delta T_{c r}$. 

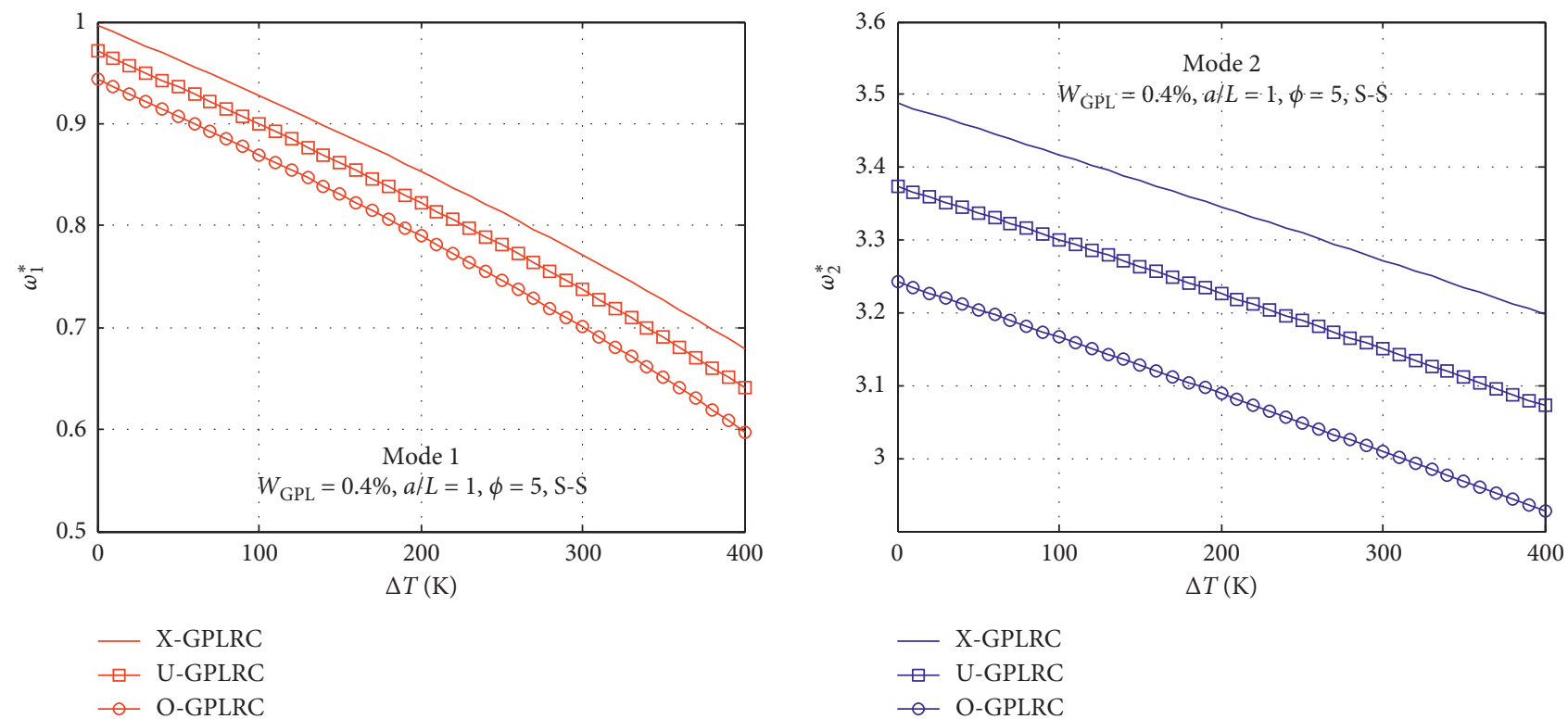

(a)

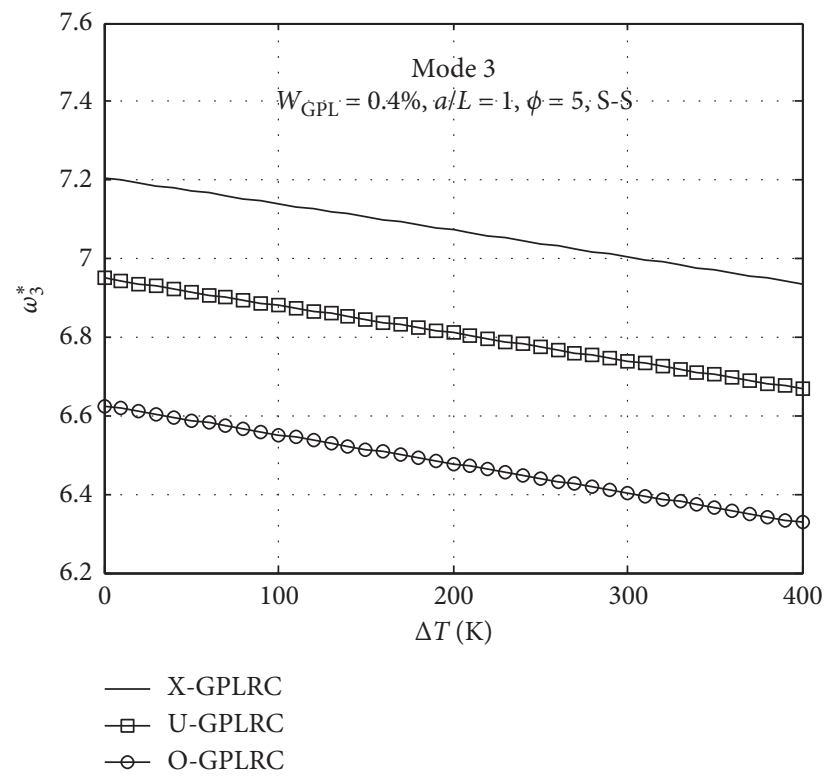

(c)

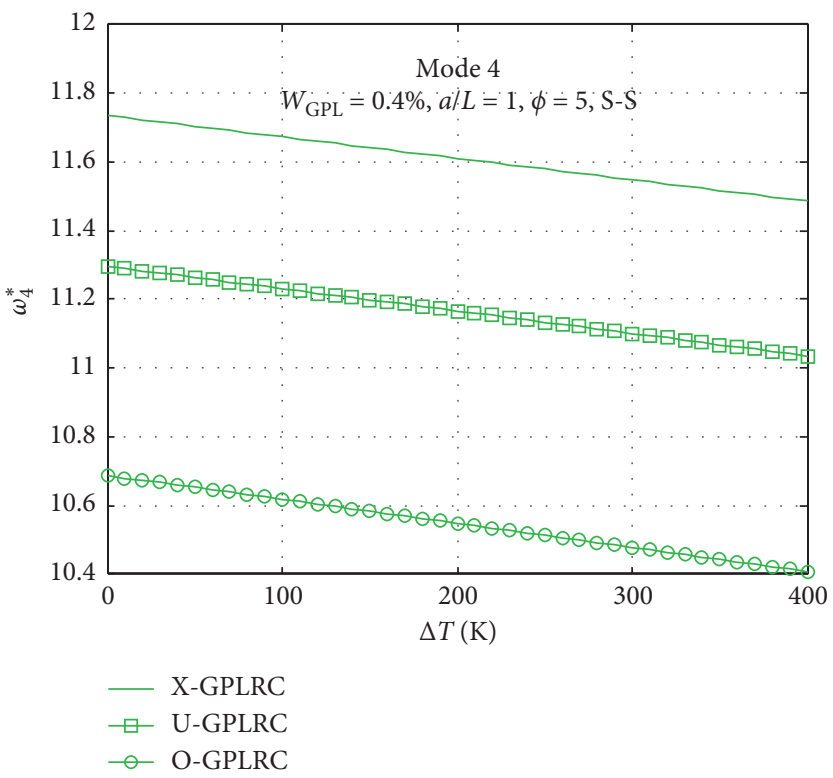

(d)

Figure 6: The dependence of the first four natural frequencies of the rotating X-, U-, and O-GPLRC beams on $\Delta T, \gamma_{0}=0.001, K_{w}^{*}=20$, $K_{s}^{*}=5$. (a) Mode 1. (b) Mode 2. (c) Mode 3. (d) Mode 4.

For the three material distribution cases of beams, the $\mathrm{X}$-GPLRC beam has the largest value of $\Delta T_{\mathrm{cr}}$ and approximately $620 \mathrm{~K}$, the O-GPLRC beam has the minimum value and approximately $480 \mathrm{~K}$, and the value of $\Delta T_{c r}$ for the U-GPLRC beam is approximately $550 \mathrm{~K}$. This rule means that, before and after this temperature, the variation of the first natural frequency depends on the change in the $W_{\mathrm{GPL}}$ ratio.

4.3. Effect of Rotational Speed. To understand the effect of the rotational speed on the free vibration response of the beam, changing the value of $\phi$ in a range of 0 to 15 , the dependencies of the first five natural frequencies of the O-GPLRC and U-GPLRC beams are shown in Figure 8. Figure 9 shows the dependence of the first four natural frequencies of the X-GPLR beam on the rotational speed and the $W_{\mathrm{GPL}}$ ratio. Figure 10 presents the first natural frequency of the X-GPLR beam on temperature with different values of the rotational speed and the $W_{\mathrm{GPL}}$ ratio. One can see the following.

As the speed of rotation of the beam increases, the stiffness of the beam increases due to the influence of the inertial force component, so the natural frequency of the beam increases. The inertia impact on the rotation speed is 


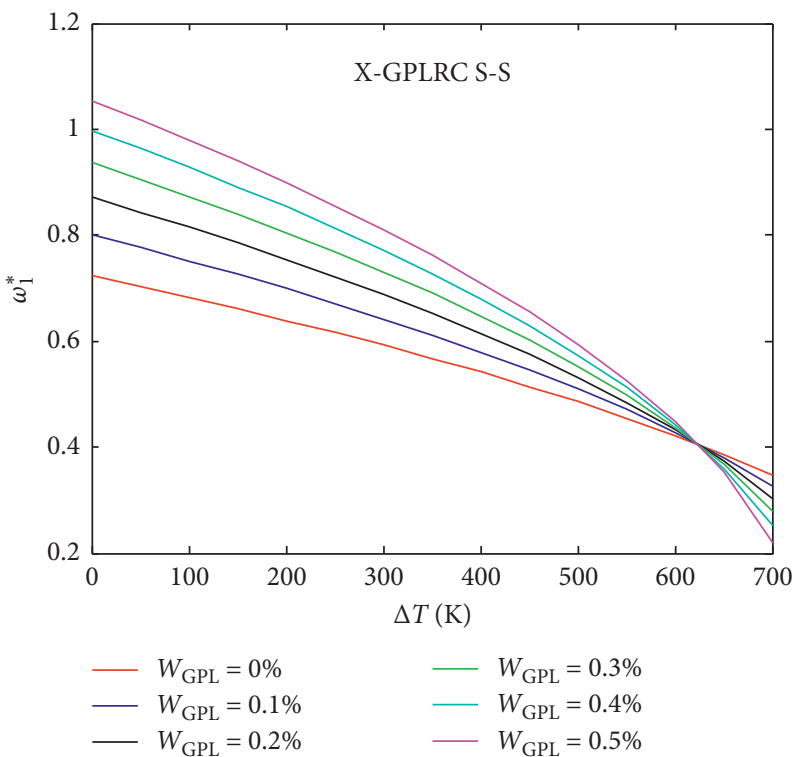

(a)

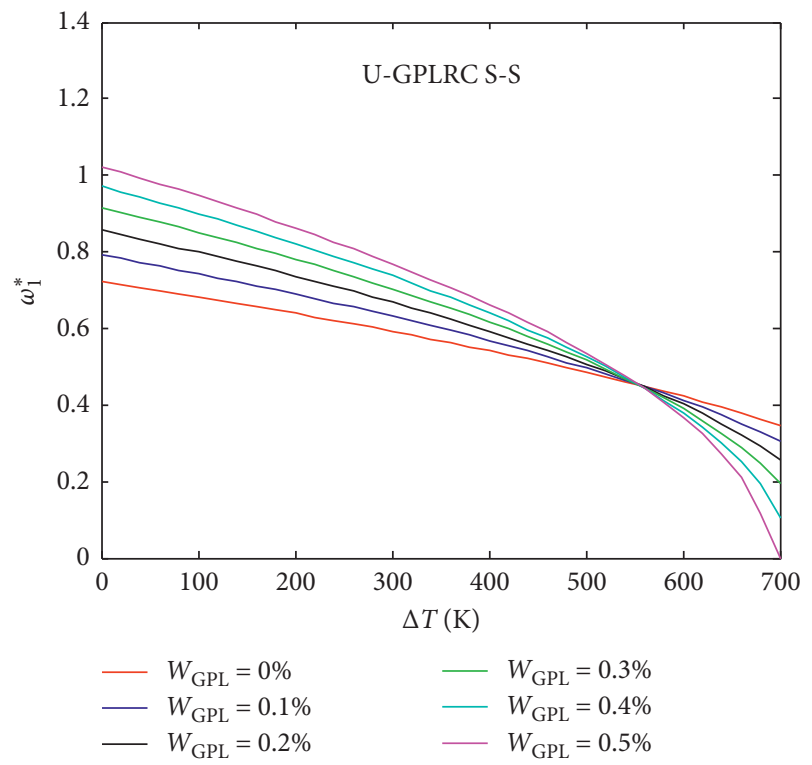

(b)

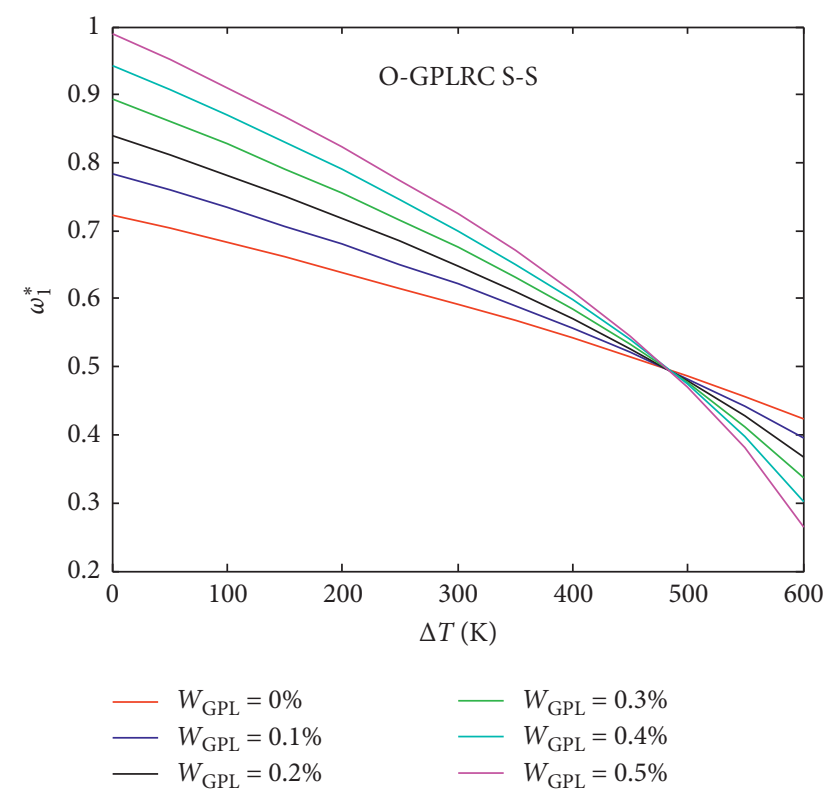

(c)

Figure 7: The dependence of the first natural frequency of the beam on temperature and the $W_{\mathrm{GPL}}$ ratio $(\mathrm{S}-\mathrm{S}), \mathrm{a} / \mathrm{L}=1, \phi=5, \gamma_{0}=0.001$, $K_{w}^{*}=20, K_{s}^{*}=5$. (a) X-GPLRC. (b) U-GPLRC. (c) O-GPLRC.

only noticeable when the rotation speed coefficient is less than 2 , but when $\phi>2$, the natural frequency of the beam changes strongly.

As the speed of rotation increases, the value of $\Delta T_{\mathrm{cr}}$ also increases, i.e., the temperature value, so that the first natural frequency of the beam independent of the graphene content also increases.

4.4. Effect of Elastic Foundation Parameters. Finally, this work considers the effect of the elastic foundation parameters of the
GPLRC beam on the free vibration response of the structure. Let $k_{w}^{*}$ increase gradually from 0 (no elastic foundation) to 100 , and $k_{s}^{*}$ gets the values from 0 to 10 . The dependence of the first natural frequency of the beam on the elastic foundation parameters and the $W_{\mathrm{GPL}}$ ratio is plotted in Figure 11. This numerical result shows that when increasing the stiffness coefficient of the elastic foundation, the natural frequency of the beam increases. In addition, the elastic foundation also affects the value of $\Delta T_{\mathrm{cr}}$; when the stiffness coefficient of the elastic foundation increases, the value of $\Delta T_{\mathrm{cr}}$ also increases, but the increase of $\Delta T_{\text {cr }}$ is not much. 


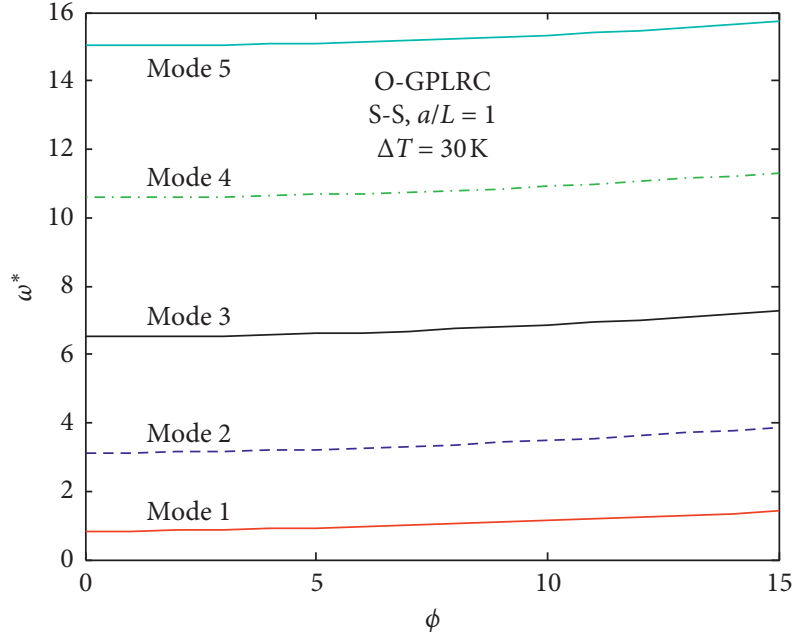

(a)

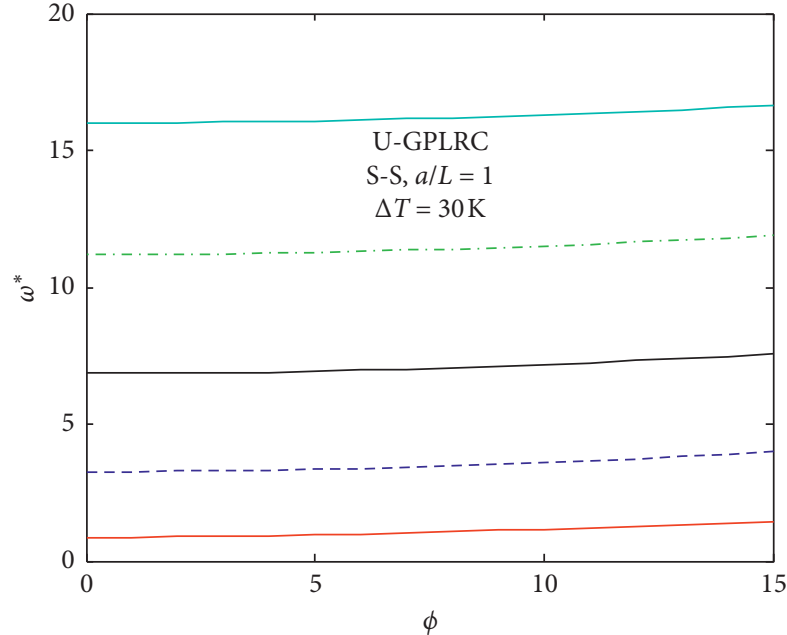

(b)

FIGURE 8: The dependence of the first five natural frequencies of the beam on the rotational speed (S-S), $a / L=1, \gamma_{0}=0.001, K_{w}^{*}=20$, $K_{s}^{*}=5$.

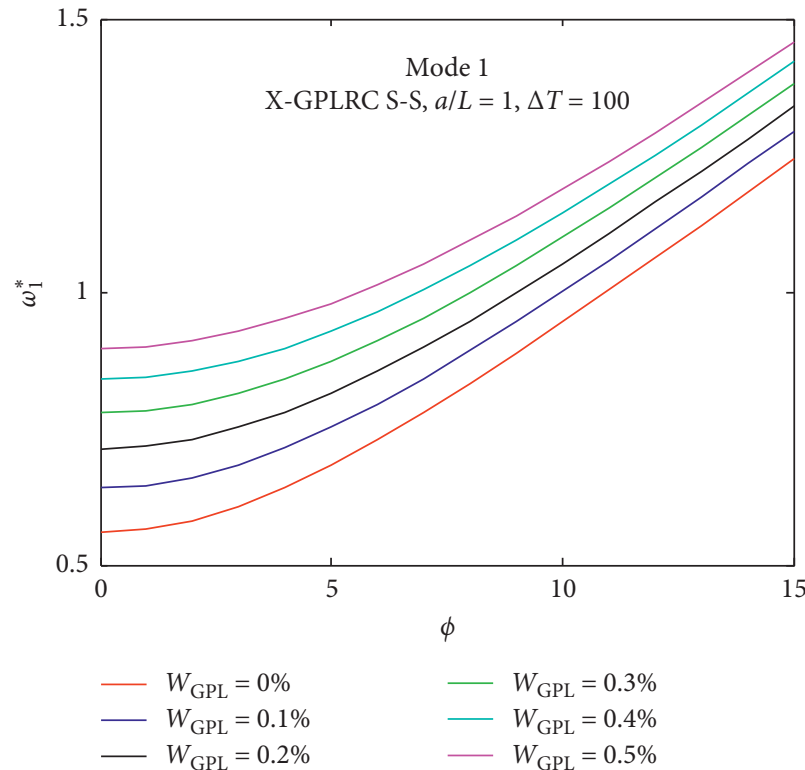

(a)

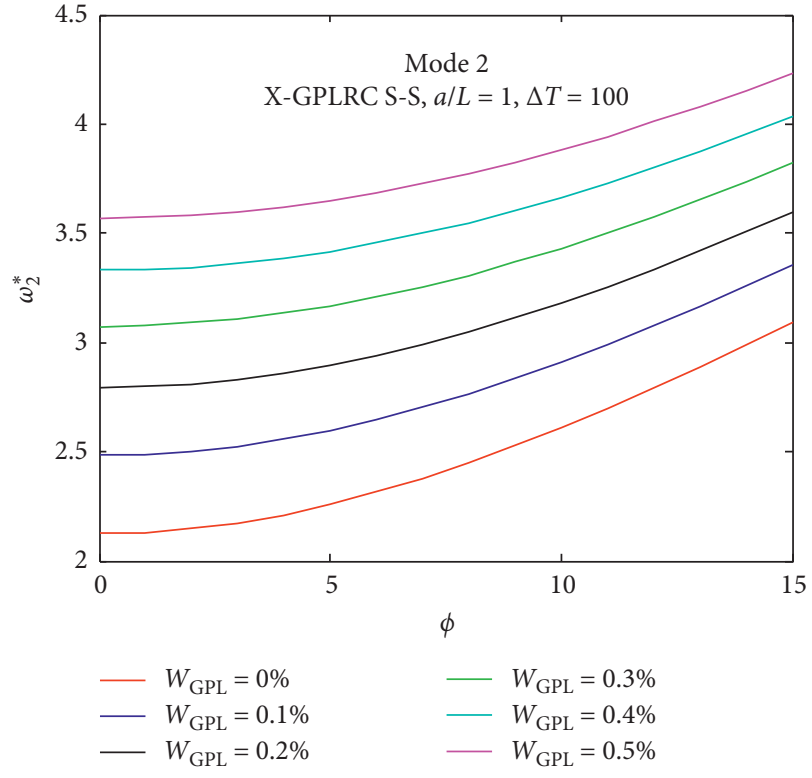

(b)

Figure 9: Continued. 


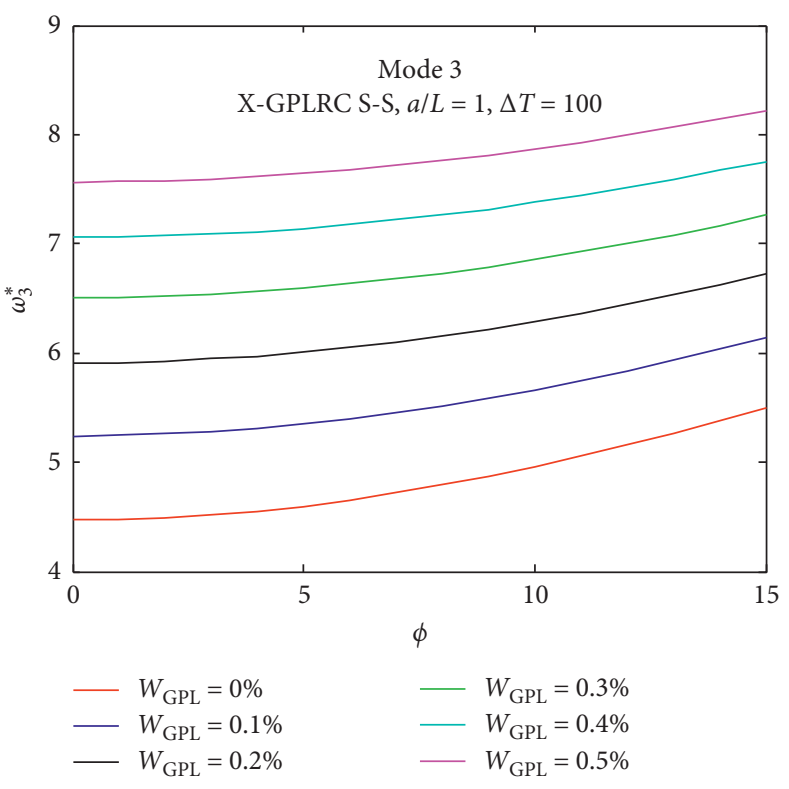

(c)

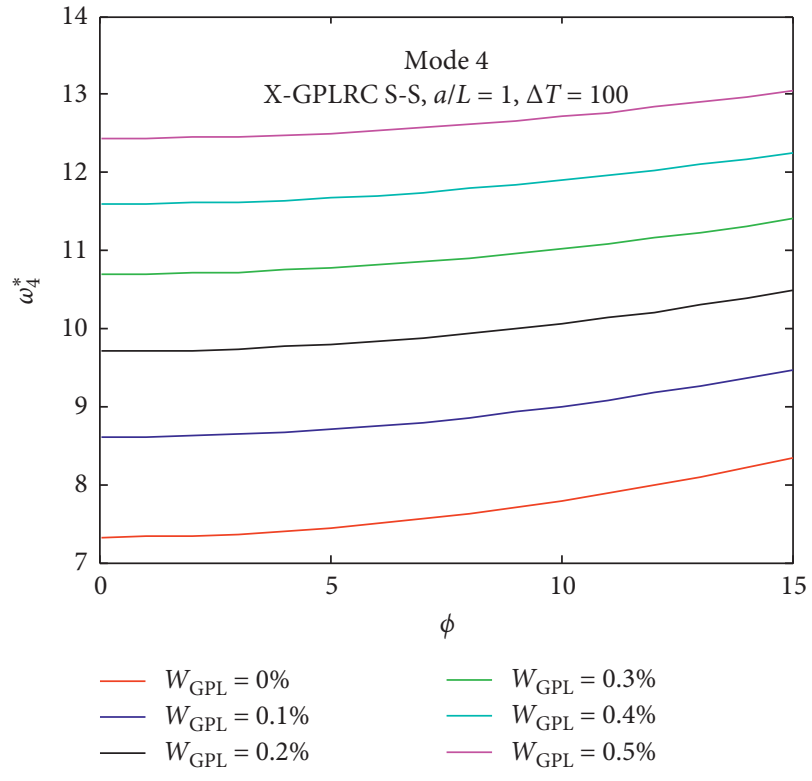

(d)

FIGURE 9: The dependence of the first four natural frequencies of the X-GPLRC beam on the rotational speed and the $W_{\mathrm{GPL}}$ ratio (S-S), $a / L=1, \gamma_{0}=0.001, K_{w}^{*}=20, K_{s}^{*}=5$.

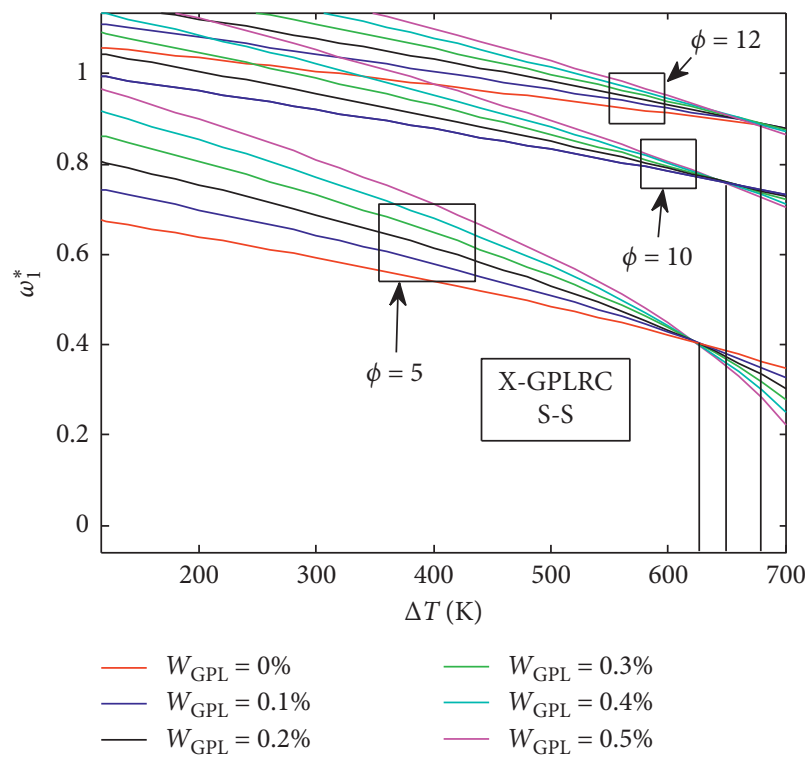

FIGURE 10: The dependence of the first natural frequency of the XGPLRC beam on the rotational speed and temperature (S-S), $a / L=1, \gamma_{0}=0.001, K_{w}^{*}=20, K_{s}^{*}=5$.

\section{Conclusions}

This work firstly uses the finite element method combined with the new shear deformation theory-type hyperbolic sine functions to investigate the free vibration analysis of rotating FG-GPLRC beams resting on two-parameter elastic foundations in the thermal environment, in which the initial geometrical imperfection is taken into account. The numerical results point out that

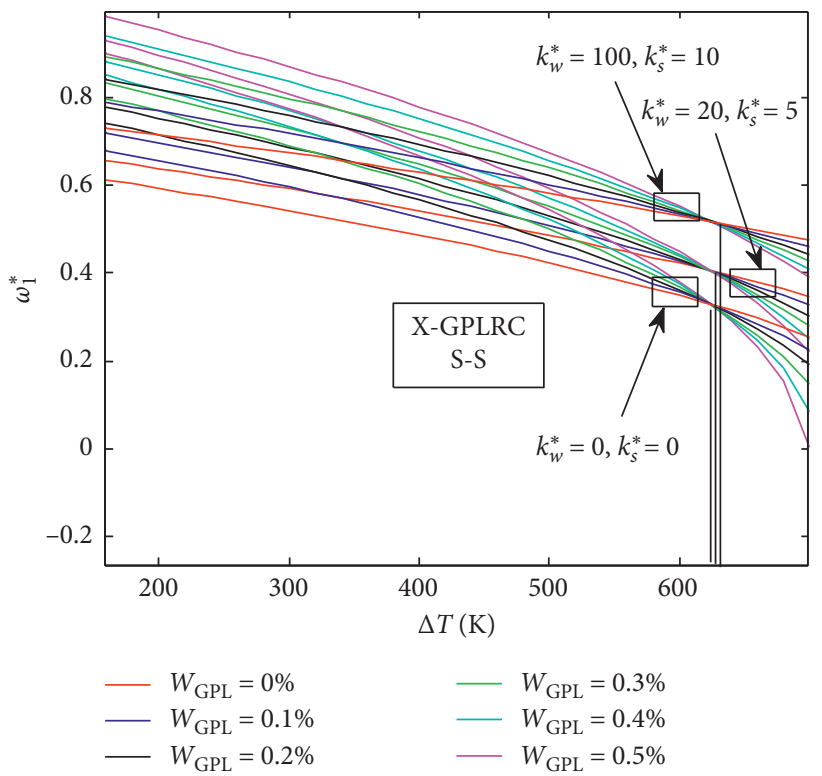

FIGURE 11: The dependence of the first natural frequency of the XGPLRC beam on the temperature and the elastic foundation parameters (S-S), $a / L=1, \phi=5, \gamma_{0}=0.001$.

(i) With the increase of the weight fractions $W_{\mathrm{GPL}}$, the natural frequency of the beam increases, and the first five natural frequencies of the beam depend nonlinearly on the $W_{\mathrm{GPL}}$ ratio.

(ii) As the temperature increases, the natural frequency of the GPLRC beam decreases, and there exists a value of temperature so that the natural frequency of the beam does not depend on the proportions of the graphene material. 
(iii) When the speed of rotation of the GPLRC beam increases, the natural frequency of the beam increases; however, when the rotational speed is small, the natural frequency increases slightly, and the natural frequency increases significantly when the rotational speed is high.

\section{Data Availability}

The data used to support the findings of this study are included within the article.

\section{Conflicts of Interest}

The authors declare that there are no conflicts of interest regarding the publication of this paper.

\section{Acknowledgments}

This study was supported by the Le Quy Don Technical University Foundation for Science and Technology Development (grant no. 4640/QDHV).

\section{References}

[1] M. H. Yas and S. Rahimi, "Thermal vibration of functionally graded porous nanocomposite beams reinforced by graphene platelets," Applied Mathematics and Mechanics, vol. 41, no. 8, pp. 1209-1226, 2020.

[2] M. Song, Y. Gong, J. Yang, W. Zhu, and S. Kitipornchai, "Nonlinear free vibration of cracked functionally graded graphene platelet-reinforced nanocomposite beams in thermal environments," Journal of Sound and Vibration, vol. 468, Article ID 115115, 2020.

[3] M. R. Barati and H. Shahverdi, "Finite element forced vibration analysis of refined shear deformable nanocomposite graphene platelet-reinforced beams," Journal of the Brazilian Society of Mechanical Sciences and Engineering, vol. 42, no. 33, pp. 1-14, 2020.

[4] Y. Wang, K. Xie, and T. Fu, "Vibration analysis of functionally graded graphene oxide-reinforced composite beams using a new Ritz-solution shape function," Journal of the Brazilian Society of Mechanical Sciences and Engineering, vol. 42, no. 180, pp. 1-14, 2020.

[5] H. R. Mojiri, S. J. Salami, Free vibration and dynamic transient response of functionally graded composite beams reinforced with graphene nanoplatelets (GPLs) resting on elastic foundation in thermal environment," Mechanics Based Design of Structures and Machines-An International Journal, 2020, Published online.

[6] M. Mohammadimehr, M. Mehrabi, and F. S. Mousavinejad, "Magneto-mechanical vibration analysis of single-/threelayered micro-Timoshenko porous beam and graphene platelet as reinforcement based on modified strain gradient theory and differential quadrature method," Journal of Vibration and Control, first published online, 2020.

[7] D. Liu, "Free vibration of functionally graded graphene platelets reinforced magnetic nanocomposite beams resting on elastic foundation," Nanomaterials, vol. 10, no. 11, p. 2193, 2020.

[8] M. S. Nematollahi, H. Mohammadi, R. Dimitri, and F. Tornabene, "Nonlinear vibration of functionally graded graphene nanoplatelets polymer nanocomposite sandwich beams," Applied Sciences, vol. 10, no. 16, p. 5669, 2020.

[9] S. Z. Tabatabaei-Nejhad, P. Malekzadeh, and M. Eghtesad, "Out-of-plane vibration of laminated FG-GPLRC curved beams with piezoelectric layers," Thin-Walled Structures, vol. 150, p. 106678, 2020.

[10] G. Manickam, P. Gupta, S. De, V. Rajamohan, and O. Polit, "Nonlinear flexural free vibrations of size-dependent graphene platelets reinforced curved nano/micro beams by finite element approach coupled with trigonometric shear flexible theory," Mechanics of Advanced Materials and Structures, 2021, Published online.

[11] E. Arshid and S. Amir, "Size-dependent vibration analysis of fluid-infiltrated porous curved microbeams integrated with reinforced functionally graded graphene platelets face sheets considering thickness stretching effect," Proceedings of the Institution of Mechanical Engineers, Part L: Journal of Materials: Design and Applications, 2021.

[12] L. H. Zhang, S. K. Lai, C. Wang, and J. Yang, "DSC regularized Dirac-delta method for dynamic analysis of FG graphene platelet-reinforced porous beams on elastic foundation under a moving load," Composite Structures, vol. 255, Article ID 112865, 2021.

[13] M. Arefi and F. Najafitabar, "Buckling and free vibration analyses of a sandwich beam made of a soft core with FGGNPs reinforced composite face-sheets using Ritz Method," Thin-Walled Structures, vol. 158, Article ID 107200, 2021.

[14] S. M. H. Hosseini, H. Arvin, and Y. Kiani, "On buckling and post-buckling of rotating clamped-clamped functionally graded beams in thermal environment," Mechanics Based Design of Structures and Machines, pp. 1-16, 2020.

[15] T. Q. Bui, T. V. Do, L. H. T. Ton et al., "On the high temperature mechanical behaviors analysis of heated functionally graded plates using FEM and a new third-order shear deformation plate theory," Composites Part B: Engineering, vol. 92, pp. 218-241, 2016.

[16] H.-N. Nguyen, T. C. Tan, D. T. Luat, V.-D. Phan, D. V. Thom, and P. V. Minh, "Research on the buckling behavior of functionally graded plates with stiffeners based on the thirdorder shear deformation theory," Materials, vol. 12, no. 8, p. 1262, 2019.

[17] N. Vu Hoai, D. Hong Doan, N. M. Khoa, T. Van Do, and H. Thi Tran, "Phase-field buckling analysis of cracked stiffened functionally graded plates," Composite Structures, vol. 217 , pp. 50-59, 2019.

[18] H. L. Ton-That, "A new C0 third-order shear deformation theory for the nonlinear free vibration analysis of stiffened functionally graded plates," Facta Universitatis, Series: Mechanical Engineering, pp. 1-21, 2020.

[19] H. Nguyen-Van, H. L. Ton-That, T. Chau-Dinh, and N. D. Dao, "Nonlinear static bending analysis of functionally graded plates using MISQ24 elements with drilling rotations," International Conference on Advances in Computational Mechanics, pp. 461-475, 2017.

[20] M. Javani, Y. Kiani, and M. R. Eslami, "Free vibration analysis of FG-GPLRC L-shaped plates implementing GDQE approach," Thin-Walled Structures, vol. 162, Article ID 107600, 2021.

[21] M. Javani, Y. Kiani, and M. R. Eslami, "Geometrically nonlinear free vibration of FG-GPLRC circular plate on the nonlinear elastic foundation," Composite Structures, vol. 261, Article ID 113515, 2021. 
[22] Y. Kiani and M. Mirzaei, "Isogeometric thermal postbuckling of FG-GPLRC laminated plates," Composite Structures, vol. 32, pp. 821-832, 2019.

[23] C. Bedon, M. Fasan, and C. Amadio, "Vibration analysis and dynamic characterization of structural glass elements with different restraints based on operational modal analysis," Buildings, vol. 9, no. 1, p. 13, 2019.

[24] C. Bedon, "Issues on the vibration analysis of in-service laminated glass structures: analytical, experimental and numerical investigations on delaminated beams," Applied Sciences, vol. 9, no. 18, p. 3928, 2019.

[25] M. Guellil, H. Saidi, F. Bourada et al., "Influences of porosity distributions and boundary conditions on mechanical bending response of functionally graded plates resting on Pasternak foundation," Steel and Composite Structures, vol. 38, no. 1, pp. 1-15, 2021.

[26] T. H. L. Bekkaye, B. Fahsi, A. A. Bousahla et al., "Porositydependent mechanical behaviors of FG plate using refined trigonometric shear deformation theory," Computers and Concrete, vol. 26, no. 5, pp. 439-450, 2020.

[27] M. S. H. Al-Furjan, A. hatami, M. Habibi, L. Shan, and A. Tounsi, "On the vibrations of the imperfect sandwich higher-order disk with a lactic core using generalize differential quadrature method," Composite Structures, vol. 257, Article ID 113150, 2021.

[28] A. Zine, A. A. Bousahla, F. Bourada et al., "Bending analysis of functionally graded porous plates via a refined shear deformation theory," Computers and Concrete, vol. 26, no. 1, pp. 63-74, 2020.

[29] M. Kaddari, A. Kaci, A. A. Bousahla et al., "A study on the structural behaviour of functionally graded porous plates on elastic foundation using a new quasi-3D model: bending and free vibration analysis," Computers and Concrete, vol. 25, no. 1, pp. 37-57, 2020.

[30] F. YAddou, M. Meradjah, A. A. Bousahla et al., "Influences of porosity on dynamic response of FG plates resting on Winkler/Pasternak/Kerr foundation using quasi 3D HSDT," Computers and Concrete, vol. 24, no. 4, pp. 347-367, 2019.

[31] M. Medani, A. Benahmed, Z. Mohamed et al., "Static and dynamic behavior of (FG-CNT) reinforced porous sandwich plate using energy principle," Steel and Composite Structures, vol. 32, no. 5, pp. 595-610, 2019.

[32] H. Berghouti, E. A. A. Bedia, A. Benkhedda, and A. Tounsi, "Vibration analysis of nonlocal porous nanobeams made of functionally graded material," Advances in Nano Research, vol. 7, no. 5, pp. 351-364, 2019.

[33] S. Khosravi, H. Arvin, and Y. Kiani, "Interactive thermal and inertial buckling of rotating temperature-dependent FG-CNT reinforced composite beams," Composites Part B: Engineering, vol. 175, Article ID 107178, 2019.

[34] Y. Kiani, H. Bagheri, and M. R. Eslami, "Asymmetric compressive stability of rotating annular plates," European Journal of Computational Mechanics, vol. 28, no. 4, pp. 325-350, 2019.

[35] H. Arvin, S. M. H. Hosseini, and Y. Kiani, "Free vibration analysis of pre/post buckled rotating functionally graded beams subjected to uniform temperature rise," Thin-Walled Structures, vol. 158, Article ID 107187, 2021.

[36] H. Bagheri, Y. Kiani, and M. R. Eslami, "Asymmetric compressive stability of rotating annular plates," European Journal of Computational Mechanics, vol. 28, no. 4, pp. 1-21, 2019.

[37] S. M. H. Hosseini, H. Arvin, and Y. Kiani, "On buckling and post-buckling of rotating clamped-clamped functionally graded beams in thermal environment," Mechanics Based
Design of Structures and Machines, pp. 1-16, 2020, Published online: 02 Jul 2020.

[38] N. T. Giang, "Free vibration exploration of rotating FGM porosity beams under axial load considering the initial geometrical imperfection," Mathematical Problems in Engineering, vol. 2021, Article ID 5519946, 16 pages, 2021.

[39] L. Li, X. Li, and Y. Hu, "Free vibration analysis of nonlocal strain gradient beams made of functionally graded material," International Journal of Engineering Science, vol. 102, pp. 77-92, 2016.

[40] H. Wu, J. Zhu, S. Kitipornchai, Q. Wang, L.-L. Ke, and J. Yang, "Large amplitude vibration of functionally graded graphene nanocomposite annular plates in thermal environments," Composite Structures, vol. 239, Article ID 112047, 2020.

[41] K. P. Soldatos, "A transverse shear deformation theory for homogeneous monoclinic plates," Acta Mechanica, vol. 94, no. 3-4, pp. 195-220, 1992.

[42] T. Huu-Tai and C. Dong-Ho, "Finite element formulation of various four unknown shear deformation theories for functionally graded plates," Finite Elements in Analysis and Design, vol. 75, pp. 50-61, 2013.

[43] C. Dejin, F. Kai, and Z. Shijie, "Flapwise vibration analysis of rotating composite laminated Timoshenko microbeams with geometric imperfection based on a re-modified couple stress theory and isogeometric analysis," European Journal of Mechanics - A/Solids, vol. 76, pp. 25-35, 2019.

[44] S. P. Timoshenko and J. M. Gere, Theory of Elastic Stability, Dover Publications, New York, NY, USA, 1989.

[45] F. Y. Cheng and C. P. Pantelides, "Dynamic Timoshenko beam-columns on elastic media," Journal of Structural Engineering, vol. 114, no. 7, pp. 1524-1550, 1988.

[46] A. Bokaian, "Natural frequencies of beams under compressive axial loads," Journal of Sound and Vibration, vol. 126, no. 1, pp. 49-65, 1988.

[47] T. Yokoyama, "Vibration analysis of Timoshenko beamcolumns on two-parameter elastic foundations," Computers \& Structures, vol. 61, no. 6, pp. 995-1007, 1996.

[48] M. Avcar and W. KMM, "Free vibration of functionally graded beams resting on Winkler-Pasternak foundation," Arabian Journal of Geosciences, vol. 11- 232, pp. 1-8, 2018.

[49] M. H. Ghayesh and M. Amabili, "Coupled longitudinaltransverse behaviour of a geometrically imperfect microbeam," Composites Part B: Engineering, vol. 60, pp. 371-377, 2014.

[50] A. D. Wright, C. E. Smith, R. W. Thresher, and J. L. C. Wang, "Vibration modes of centrifugally stiffened beams," Journal of Applied Mechanics, vol. 49, no. 1, pp. 197-202, 1982.

[51] H. H. Yoo and S. H. Shin, "Vibration analysis of rotating cantilever beams," Journal of Sound and Vibration, vol. 212, no. 5, pp. 807-828, 1998. 